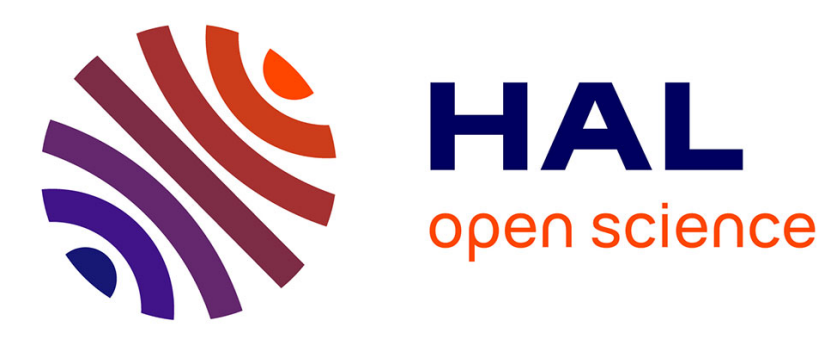

\title{
Li6SiO4Cl2: a hexagonal argyrodite based on antiperovskite layer stacking
}

\author{
Alexandra Morscher, Matthew Dyer, Benjamin Duff, Guopeng Han, Jacinthe \\ Gamon, Luke Daniels, Yun Dang, T. Wesley Surta, Craig Robertson, Frédéric
} Blanc, et al.

\section{To cite this version:}

Alexandra Morscher, Matthew Dyer, Benjamin Duff, Guopeng Han, Jacinthe Gamon, et al.. Li6SiO4Cl2: a hexagonal argyrodite based on antiperovskite layer stacking. Chemistry of Materials, 2021, 33 (6), pp.2206-2217. 10.1021/acs.chemmater.1c00157 . hal-03356815

\section{HAL Id: hal-03356815 https://hal.science/hal-03356815}

Submitted on 7 Oct 2021

HAL is a multi-disciplinary open access archive for the deposit and dissemination of scientific research documents, whether they are published or not. The documents may come from teaching and research institutions in France or abroad, or from public or private research centers.
L'archive ouverte pluridisciplinaire HAL, est destinée au dépôt et à la diffusion de documents scientifiques de niveau recherche, publiés ou non, émanant des établissements d'enseignement et de recherche français ou étrangers, des laboratoires publics ou privés. 


\section{$\mathrm{Li}_{6} \mathrm{SiO}_{4} \mathrm{Cl}_{2}:$ A Hexagonal Argyrodite based on anti-perovskite layer stacking}

Alexandra Morscher, ${ }^{a}$ Matthew S. Dyer, ${ }^{a}$ Benjamin B. Duff,,${ }^{a, b}$ Guopeng Han, ${ }^{a}$ Jacinthe Gamon, ${ }^{a}$ Luke M. Daniels, ${ }^{a}$ Yun Dang, ${ }^{a}$ T. Wesley Surta, ${ }^{a}$ Craig M. Robertson, ${ }^{a}$ Frédéric Blanc, ${ }^{a, b}$ John B. Claridge ${ }^{a}$ and Matthew J. Rosseinsky*a

a Department of Chemistry, University of Liverpool, Crown Street, L69 7ZD Liverpool, UK.

b Stephenson Institute for Renewable Energy, University of Liverpool, Peach Street L69 7ZF Liverpool, UK.

*Corresponding Author: m.j.rosseinsky@liverpool.ac.uk

\section{Abstract:}

A hexagonal analogue, $\mathrm{Li}_{6} \mathrm{SiO}_{4} \mathrm{Cl}_{2}$, of the cubic lithium argyrodite family of solid electrolytes is isolated by a computation-experiment approach. We show that the argyrodite structure is equivalent to the cubic anti-perovskite solid electrolyte structure through anion site and vacancy ordering within a cubic stacking of two close-packed layers. Construction of models that assemble these layers with the combination of hexagonal and cubic stacking motifs, both well-known in the large family of perovskite structural variants, followed by energy minimisation identifies $\mathrm{Li}_{6} \mathrm{SiO}_{4} \mathrm{Cl}_{2}$ as a stable candidate composition. Synthesis and structure determination demonstrate that the material adopts the predicted lithium site-ordered structure with low lithium conductivity of $\sim 10^{-10} \mathrm{~S} \mathrm{~cm}^{-1}$ at room temperature, and the predicted hexagonal argyrodite structure above an order-disorder transition at 469.3(1) $\mathrm{K}$. This transition establishes dynamic Li site disorder analogous to that of cubic argyrodite solid electrolytes in hexagonal argyrodite $\mathrm{Li}_{6} \mathrm{SiO}_{4} \mathrm{Cl}_{2}$ and increases $\mathrm{Li}$ ion mobility observed via NMR and $\mathrm{AC}$ impedance spectroscopy. The compositional flexibility of both argyrodite and perovskite alongside this newly established structural connection which enables the use of hexagonal and cubic stacking motifs identifies a wealth of unexplored chemistry significant to the field of solid electrolytes.

\section{Introduction}

Compounds related to the mineral argyrodite $\left(\mathrm{Ag}_{8} \mathrm{GeS}_{6}\right)$ have been the focus of considerable interest for over half a century. The argyrodite family is compositionally flexible, with the general formula $A_{(12-n-y) / m}^{m+} L_{6-y}^{n+} X_{6-y}^{2-} Y_{y}^{-}(A=$ $\mathrm{Ag}^{+}, \mathrm{Cu}^{+}, \mathrm{Cd}^{2+}$ etc.; $\mathrm{L}=\mathrm{Ga}^{3+}, \mathrm{Si}^{4+}, \mathrm{Ge}^{4+}, \mathrm{P}^{5+}$ etc $\left.; \mathrm{X}=\mathrm{S}^{2-}, \mathrm{Se}^{2-}, \mathrm{Te}^{2-} ; \mathrm{Y}=\mathrm{Cl}^{-}, \mathrm{Br}^{-}, \mathrm{I}^{-}\right),{ }^{1}$ where $A$ cation content can vary from 3.25 to 9 in order to maintain charge neutrality. This family of compounds contains examples of fast $\mathrm{Ag}^{+}$ and $\mathrm{Cu}^{+}$ion conductors (e.g., $\mathrm{Cu}_{6} \mathrm{PS}_{5} \mathrm{Cl},{ }^{1}$ and $\mathrm{Ag}_{7} \mathrm{NbS}_{6}{ }^{2}$ ) as well as materials interesting for their non-linear optical properties (e.g., $\mathrm{Cd}_{3.25} \mathrm{PS}_{5.5} \mathrm{l}_{0.5^{1}}$ ) and thermoelectric properties (e.g., $\mathrm{Ag}_{8} \mathrm{SnSe}_{6}{ }^{3}$ ).

The reported crystal structures of argyrodites are related to the high temperature $F \overline{4} 3 m$ cubic polymorph of $\mathrm{Ag}_{8} \mathrm{GeS}_{6}$, where $A$ cations often demonstrate extended dynamic disorder. Static ordering of cations at low temperatures, along with corresponding structural displacements, can lead to low temperature polymorphs with lower symmetry. ${ }^{4,5}$ This dynamic disorder in higher symmetry polymorphs has led to extensive investigations of argyrodites as potential solid-state electrolytes in all solid-state lithium ion batteries (ASSBs). ${ }^{6,7}$ In the lithiumcontaining argyrodites, the introduction of a halide anion transforms the room temperature orthorhombic polymorph 
(Li7 PCh $\left(C h=\mathrm{S}\right.$, Se): space group Pna2 1 ) into cubic symmetry $\left(\mathrm{Li}_{6} \mathrm{PC} h_{5} X(\mathrm{X}=\mathrm{Cl}, \mathrm{Br}\right.$, I): space group $F \overline{4} 3 m)$, while charge compensation occurs via reduction of the lithium content. The latter cubic phase exhibits an order-disorder phase transition from static order (LT cubic phase) to extended dynamic disorder (HT cubic phase), with delocalization of the lithium distribution. ${ }^{8}$ In cubic oxide analogues such as $\mathrm{Li}_{6} \mathrm{PO} \mathrm{O}_{5} \mathrm{Br}$, this phase transition does not occur, and lithium localization within the $F \overline{4} 3 \mathrm{~m}$ structure is maintained over a wide temperature range (173$873 \mathrm{~K}) .{ }^{9} \mathrm{In}$ the ordered $F \overline{4} 3 \mathrm{~m}$ structure of $\mathrm{Li}_{6} \mathrm{PO}_{5} \mathrm{Br}$, lithium ions fully occupy a single crystallographic $24 \mathrm{~g}$ position. In the dynamically disordered HT $F \overline{4} 3 m$ structure of the lithium sulphide argyrodites, the additional available lithium sites (Wyckoff position 48h) and extended diffusion of $\mathrm{Li}^{+}$are linked to a dramatic increase in ionic conductivity by six orders of magnitude. ${ }^{10,11}$ The most highly conducting Li-containing argyrodites are based on mixed sulphidehalide compositions e.g., $\mathrm{Li}_{6} \mathrm{PS}_{5} \mathrm{Br}^{6}$ and $\mathrm{Li}_{6.35} \mathrm{P}_{0.65} \mathrm{Si}_{0.35} \mathrm{~S} 5 \mathrm{Br}$ in which $\mathrm{Li}^{+}$is delocalized across $48 \mathrm{~h}$ and $24 \mathrm{~g}$ positions. ${ }^{12}$

The high-temperature $F \overline{4} 3 m$ argyrodite structure has previously been described in terms of tetrahedral closepacking $^{1}$ or as localised pseudo-octahedral cages of $A$ cations surrounding one anion, and separated by the other anions. ${ }^{10,11}$ In this work, we establish a new relationship between the structures of argyrodites and those of cubic anti-perovskites, which are themselves good conductors of lithium ions (i.e., $\mathrm{Li}_{3} \mathrm{OCl}_{1-x} \mathrm{Br}_{x}$ ). ${ }^{13}$ We extend this relationship, which provides a framework for designing lithium ion conductors, from cubic to hexagonal antiperovskites and thus propose the lithium hexagonal argyrodite family, computationally identifying several new compositional targets within this family. $\mathrm{Li}_{6} \mathrm{SiO}_{4} \mathrm{Cl}_{2}$ is then successfully synthesized following these predictions based on mixed cubic and hexagonal stacking, and shows analogous dynamical cation site disorder to cubic argyrodites which is required for Li transport.

\section{Experimental Procedures}

\subsection{Computational methods}

Periodic plane-wave based density functional theory (DFT) calculations were performed using the VASP code (version 5.4.4). ${ }^{14}$ All calculations were performed with the projector augmented wave method, ${ }^{15}$ a plane-wave cutoff energy of $700 \mathrm{eV}$ and a $k$-point spacing of $0.15 \AA^{-1}$. Geometry optimisation of both atomic positions and unit cell parameters was terminated once all forces fell below $0.001 \mathrm{eV} \AA^{-1}$. The PBE functional ${ }^{16}$ was used to calculate relative energies and mechanical properties, and the PBEsol functional ${ }^{17}$ used for direct comparison between computational and experimental crystal structures. The convex hull of energies for all reported phases in the Li-Si$\mathrm{O}-\mathrm{Cl}-\mathrm{Br}$ and $\mathrm{Li}-\mathrm{Si}-\mathrm{O}-\mathrm{Cl}-\mathrm{I}$ phase fields were calculated using pymatgen. ${ }^{18}$ Normal mode calculations were performed using the harmonic approximation, with finite displacements of $0.01 \AA$ and including distortions of the unit cell. This allowed the calculation of elastic constants, including the bulk and shear modulus. ${ }^{19}$ For comparison with existing compounds the elastic constants of $\mathrm{Li}_{3} \mathrm{OBr}(\mathrm{Pm} \overline{3} m \text { structure })^{20}$ and $\mathrm{Li}_{6} \mathrm{PS}_{5} \mathrm{Br}$ (Cc structure of $\left.\mathrm{Li}_{6} \mathrm{PS}_{5}\right)^{21}$ were computed using the same method.

\subsection{Synthesis}

Materials

$\mathrm{Li}_{2} \mathrm{CO}_{3}(99.99 \%), \mathrm{SiO}_{2}$ (silica gel, technical grade, particle size 40-63 $\mu \mathrm{m}$ ) and $\mathrm{LiCl}(>99.0 \%$ ) were purchased from Sigma Aldrich. 


\section{Synthesis of $\mathrm{Li}_{4} \mathrm{SiO}_{4}{ }^{22}$}

Precursors were dried overnight at $473 \mathrm{~K}$ before weighing. $\mathrm{Li}_{2} \mathrm{CO}_{3}\left(1.2331 \mathrm{~g}\right.$, ) and $\mathrm{SiO}_{2}(0.5013 \mathrm{~g})$ were weighed according to the stoichiometric 2:1 ratio. The powders were ground with an agate pestle and mortar for $15 \mathrm{~min}$, placed into an alumina crucible and heated in air to $1073 \mathrm{~K}$ at a ramp rate of $5 \mathrm{~K} \mathrm{~min}^{-1}$, held at $1073 \mathrm{~K}$ for $12 \mathrm{~h}$ and cooled at a ramp rate of $5 \mathrm{~K} \mathrm{~min}^{-1}$. The resulting product was ground to obtain a fine powder, which was then used as a precursor in the final synthesis step.

\section{Synthesis of $\mathrm{Li}_{6} \mathrm{SiO}_{4} \mathrm{Cl}_{2-x} \mathrm{Br}_{x}$}

$\mathrm{Li}_{4} \mathrm{SiO}_{4}, \mathrm{LiCl}$ and $\mathrm{LiBr}$ were vacuum dried overnight (under $10^{-4} \mathrm{mbar}$ ) before placing them in an Ar-filled glove box. All precursors and resulting powders were then handled in an Ar-filled glove box. $\mathrm{LiCl}, \mathrm{LiBr}$ and $\mathrm{Li}_{4} \mathrm{SiO}_{4}$ were mixed in the stoichiometric ratio, ground with an agate pestle and mortar for $15 \mathrm{~min}$ and transferred to an alumina crucible. The crucible was placed in a silica tube which was sealed under vacuum $\left(<10^{-4} \mathrm{mbar}\right)$. The tube was heated to 798 $\mathrm{K}$ at a ramp rate $5 \mathrm{~K} \mathrm{~min}^{-1}$, held at $798 \mathrm{~K}$ for $12 \mathrm{~h}$ and cooled at a rate of $5 \mathrm{~K} \mathrm{~min}^{-1}$. Once cool, the silica tube was opened inside the Ar glovebox, and the powder ground in a pestle and mortar for further characterisation.

Single crystals of $\mathrm{Li}_{6} \mathrm{SiO}_{4} \mathrm{Cl}_{2}$ were grown by mixing $\mathrm{LiCl}$ and $\mathrm{Li}_{4} \mathrm{SiO}_{4}$ in the stoichiometric ratio, heating the mixture to $883 \mathrm{~K}$ at a ramp rate of $5 \mathrm{~K} \mathrm{~min}^{-1}$, annealing it for $3 \mathrm{~h}$ and slow cooling at $3 \mathrm{~K} \mathrm{~h}^{-1}$ to room temperature.

\subsection{Powder X-ray Diffraction}

Routine assessment of sample purity was carried out using a Bruker D8 Discover diffractometer with monochromatic Cu radiation ( $\mathrm{Ka}_{1}, \lambda=1.54056 \AA$ ) in Debye Scherrer transmission geometry with sample powders loaded into $0.5 \mathrm{~mm}$ borosilicate glass capillaries.

Synchrotron X-ray diffraction (SXRD) was performed at Diamond Light Source U.K., on high-resolution beamline $111,{ }^{23}$ at $\lambda=0.826552 \AA$. The pattern was recorded in transmission mode $\left[0^{\circ}<2 \theta<150^{\circ}\right]$ using a multi analyser crystal (MAC) detector. The sample was introduced into a $1.0 \mathrm{~mm}$ diameter borosilicate glass capillary. The experiment was performed at room temperature.

Synchrotron variable temperature $\mathrm{X}$-ray diffraction (VT-XRD) was performed in transmission mode using a position sensitive detector (PSD, $\lambda=0.82660 \AA$ ) on a sample which was introduced into a $1.0 \mathrm{~mm}$ diameter silica capillary. The experiment was performed in the temperature range $298-798 \mathrm{~K}$ in $25 \mathrm{~K}$ steps on heating, then cooled directly to room temperature to assess reversibility.

Rietveld refinements were carried out using TOPAS Academic. ${ }^{24}$ Initially, Pawley fits were performed on SXRD data, refining the lattice parameters and the background using a Chebyshev function with 12 parameters. The peak shape was modeled using a Pseudo-Voigt function (high temperature patterns) and a Thomson - Cox function (room temperature patterns). Refined parameters from final Pawley fits were then used as starting points for Rietveld refinements where the following parameters were refined: (1) scale factor, (2) atomic coordinates (3) isotropic ( $\mathrm{Li}, \mathrm{Si}, \mathrm{O})$ and anisotropic $(\mathrm{Cl})$ displacement parameters, and (4) atomic occupancies: the occupancies of $\mathrm{Cl}, \mathrm{O}$ and $\mathrm{Li}$ were refined whilst the occupancy of the Si site was set to the nominal value.

\subsection{Single crystal X-ray diffraction}

A twinned crystal was examined with a Rigaku MicroMax-007 HF X-ray generator equipped with a Mo-Ka rotatinganode microfocus source and a Saturn 724+ detector. The data were collected at $100 \mathrm{~K}$. Refinement of the cell parameters, indexing of twin components, and reduction of the data were performed on the obtained diffraction images with use of the software package CrysAlisPro. ${ }^{25}$ The volume ratio of the twin components was about $1 / 1$. 
The degree of overlap of two components is around $1 \%$. The twin operator is $92.82^{\circ}$ rotation around the -0.590 .37$ -0.72 reciprocal axis. The detwinned HKLF4 format file was used for structure solution using Olex2. ${ }^{26}$ The crystal structure was solved with Intrinsic Phasing method provide by the ShelXT ${ }^{27}$ structure solution program. Refinements were carried out with the ShelXL ${ }^{28}$ refinement package using Least Squares minimization.

\subsection{Differential Scanning Calorimetry}

Heat flux profiles were measured from $15.1 \mathrm{mg}$ of powdered sample in a $40 \mu \mathrm{L}$ aluminium crucible cold-welded under $\mathrm{Ar}$ atmosphere $\left(<0.1 \mathrm{ppm} \mathrm{O}_{2}, \mathrm{H}_{2} \mathrm{O}\right)$ using a Netzsch DSC $404 \mathrm{~F} 1$ differential scanning calorimeter. Data were recorded on heating to $823 \mathrm{~K}$ and then cooling to $323 \mathrm{~K}$ using heating and cooling rates of $10 \mathrm{~K} \mathrm{~min}^{-1}$ under a constant $50 \mathrm{~mL} \mathrm{~min}^{-1}$ flow of helium. The transition temperature is the average of the values obtained from both the heating and cooling curves, which were extracted through peak fitting.

\subsection{AC Impedance Spectroscopy and DC polarisation}

A pellet of $\mathrm{Li}_{6} \mathrm{SiO}_{4} \mathrm{Cl}_{2}$ was made by uniaxially pressing $\sim 30 \mathrm{mg}$ of material in an $8 \mathrm{~mm}$ cylindrical steel die at a pressure of $125 \mathrm{MPa}$. The pellet was sintered in an evacuated, flame dried silica tube for $12 \mathrm{~h}$ at $848 \mathrm{~K}$. Using this method, a relative density of $84 \%$ was achieved.

AC impedance measurements were conducted using an impedance analyser (Keysight impedance analyser E4990A). A sputtered gold coating of $300 \mathrm{~nm}$ thickness was used as the ion blocking electrodes. Sputtering was achieved under argon atmosphere using a Q150R sputter coater and temperature-dependent conductivity measurements were performed under an argon atmosphere over a frequency range of $2 \mathrm{MHz}-20 \mathrm{~Hz}$ (with an amplitude of $100 \mathrm{mV}$ ). Measurements were performed in the temperature range $333-575 \mathrm{~K}$ in $20 \mathrm{~K}$ steps. The ZView2 program ${ }^{29}$ was used to fit the impedance spectra with an equivalent circuit.

A pellet of $84 \%$ relative density was used for DC potentiation polarisation measurements. DC polarisation data was collected at $300{ }^{\circ} \mathrm{C}$ on an Au|Li6SiO4Cl2|Au symmetric cell by applying constant potentials of $0.05,0.1,0.5$ and $1 \mathrm{~V}$ for 7200 s and monitoring the current variation with time. Once a constant current was achieved the current was recorded and plotted against the applied voltage allowing for the electronic conductivity $\left(\sigma_{e}\right)$ to be extracted from following equation

$$
\sigma_{e}=\frac{U l}{A I}
$$

Where $U$ refers to the polarisation voltage, $l$ to the pellet thickness, $A$ to the Au electrode area and $I$ to the current, respectively

\subsection{Nuclear magnetic resonance (NMR) spectroscopy}

${ }^{29} \mathrm{Si}$ magic-angle spinning (MAS) NMR spectra were recorded with a $4 \mathrm{~mm}$ HXY MAS probe in double resonance mode on a Bruker 9.4 T Avance III HD spectrometer. ${ }^{29} \mathrm{Si}$ NMR data was obtained using a pulse length of $5 \mu \mathrm{s}$ at a radio frequency (rf) amplitude of $50 \mathrm{kHz}$ and at a MAS rate of $\mathrm{vr}_{r}=10 \mathrm{kHz}$. The sample was packed into a rotor in an Ar-filled glovebox to eliminate exposure to air and moisture. ${ }^{29} \mathrm{Si}$ shifts were externally referenced to Octakis(trimethylsiloxy)silsesquioxane ${ }^{2}{ }^{29} \mathrm{Si}$ chemical shifts were externally referenced to the lowest frequency signal of octakis(trimethylsiloxy)silsesquioxane at $-109 \mathrm{ppm},{ }^{30}$ relative to tetramethylsilane primary reference at 0.0 ppm).

Variable temperature ${ }^{7} \mathrm{Li}$ NMR experiments were recorded with a $4 \mathrm{~mm}$ HX High Temperature MAS Probe on a 9.4 T Bruker Avance III HD spectrometer under static conditions with the $X$ channel tuned to ${ }^{7} \mathrm{Li}$ at $\omega_{0} / 2 \pi\left({ }^{7} \mathrm{Li}\right)=156$ 
$\mathrm{MHz}$. The sample was sealed in glass ampoule and the spectra were recorded with a pulse length of $1.5 \mu \mathrm{s}$ at a rf field amplitude of $\omega_{1} / 2 \pi=83 \mathrm{kHz}$ and referenced to $10 \mathrm{M} \mathrm{LiCl}$ in $\mathrm{D}_{2} \mathrm{O}$ at $0 \mathrm{ppm}$.

The homonuclear dipolar coupling constant between two ${ }^{7} \mathrm{Li}$ nuclear spins d7Li7Li (in $\mathrm{Hz}$ ) can be calculated via the following expression:

$$
\mathrm{d}_{7 \mathrm{Li} 7 \mathrm{Li}}=-\frac{\mu_{0}}{8 \pi^{2}} \frac{\hbar \gamma_{7 \mathrm{Li}}^{2}}{\mathrm{r}_{\mathrm{LiLi}}^{3}}
$$

where $\mu_{0}$ is the permeability of free space, $\hbar$ the reduced Planck's constant, Y7Li the gyromagnetic ratio of $7 \mathrm{Li}$ and $r_{i j}$ the Li-Li distance.

Temperature calibrations were performed using the chemical shift thermometers $\mathrm{Pb}\left(\mathrm{NO}_{3}\right)_{2}$ using ${ }^{207} \mathrm{~Pb} \mathrm{NMR}{ }^{31}$ and Cul and $\mathrm{CuBr}$ using ${ }^{63} \mathrm{Cu} \mathrm{NMR}^{32},{ }^{33}$ The errors associated with this method were calculated using the isotropic peak line broadening and range from $5-20 \mathrm{~K}$.

\subsection{Maximum entropy methods}

Maximum entropy method (MEM) analysis was performed on SXRD and VT-XRD data using the software Jana2006 ${ }^{34}$ and BayMEM. ${ }^{35}$ Rietveld models from Topas were input into Jana2006, which was used to extract $F_{\text {obs }}$ and generate MEM inputs. BayMEM was used to calculate the electron density distribution using the $F_{o b s}$ and the number of electrons in the nominal stoichiometry. Calculations using the number of electrons associated with a $10 \% \mathrm{Li}$ deficiency were also performed for all models investigated and found to have negligible impact in the resulting electron density distributions. All MEM results were visualized in the VESTA crystal structure visualization software. ${ }^{36}$

\section{Results and Discussion}

\subsection{Selection of target compounds by structural analogy between argyrodite and perovskite}

We describe the relationship between the argyrodite structure, exemplified by $\mathrm{Li}_{6} \mathrm{PO}_{5} \mathrm{Br}$ (Figure 1a), and the cubic anti-perovskite structure. In analogy with perovskites of general formula $\mathrm{ABX}_{3}, \mathrm{Li}_{6} \mathrm{PO}{ }_{5} \mathrm{Br}$ can be written as: $\left[\left(\left(\mathrm{PO}_{4}\right)_{0.5} \mathrm{Br} 0.5\right)\left(\mathrm{O}_{0.5} \square_{0.5}\right) \mathrm{Li}_{3}\right]_{2}$, where $\square$ is a vacancy. As such, $\mathrm{Li}_{6} \mathrm{PO}_{5} \mathrm{Br}$ could be considered as an inverse double perovskite. When viewed as a cubic anti-perovskite, the lithium ions in $\mathrm{Li}_{6} \mathrm{PO}_{5} \mathrm{Br}$ replace the anion positions in the conventional cubic perovskite (e.g., $\mathrm{SrTiO}_{3},{ }^{37}$ Figure $1 \mathrm{~b}$ ). The phosphate polyanions and bromide anions replace the larger A-site cations in a rock-salt ordered fashion. As the cubic perovskite can be represented as a cubic closepacked stacking of $A X_{3}$ layers along [111], here the cubic stacking is an alternation of $\mathrm{Li}_{3} \mathrm{Br}$ and $\mathrm{Li}_{3} \mathrm{PO}_{4}$ layers that produces the rock-salt anion ordering. The remaining, isolated oxide anions then occupy half of the octahedral Bsite positions between these layers also in an ordered manner, leaving the other half of the B-sites vacant. The $\mathrm{P}$ O bond vector of each tetrahedral $\left(\mathrm{PO}_{4}\right)^{3-}$ anion is directed towards the vacant $\mathrm{B}$-sites, coupling the rock salt order of the two $A$ site anions to the anion vacancy defect ordering on the B site. Rock-salt order of $50 \%$ B-site vacancies occurs in the structure of well-known $\mathrm{K}_{2} \mathrm{PtCl}_{6}{ }^{38}$ (Figure 1c). When considering these structural similarities between the lithium argyrodites and the lithium anti-perovskites, it is evident that the lithium sites in both structures are topologically equivalent. As a result, both structures share the same network of connectivity between lithium sites (Figure $1 \mathrm{~d}$ and $1 \mathrm{e}$ ), suggesting that the underlying mechanism for high ionic conductivity is common to both material 
families. The existence of both cubic and hexagonal perovskites associated with the distinct stackings of the $\mathrm{AX}_{3}$ layers suggests the existence of hexagonal $\mathrm{Li}$ argyrodites that are also based on alternating $\mathrm{Li} i_{3} \mathrm{Br}$ and $\mathrm{Li}_{3} \mathrm{PO}_{4}$ stackings.
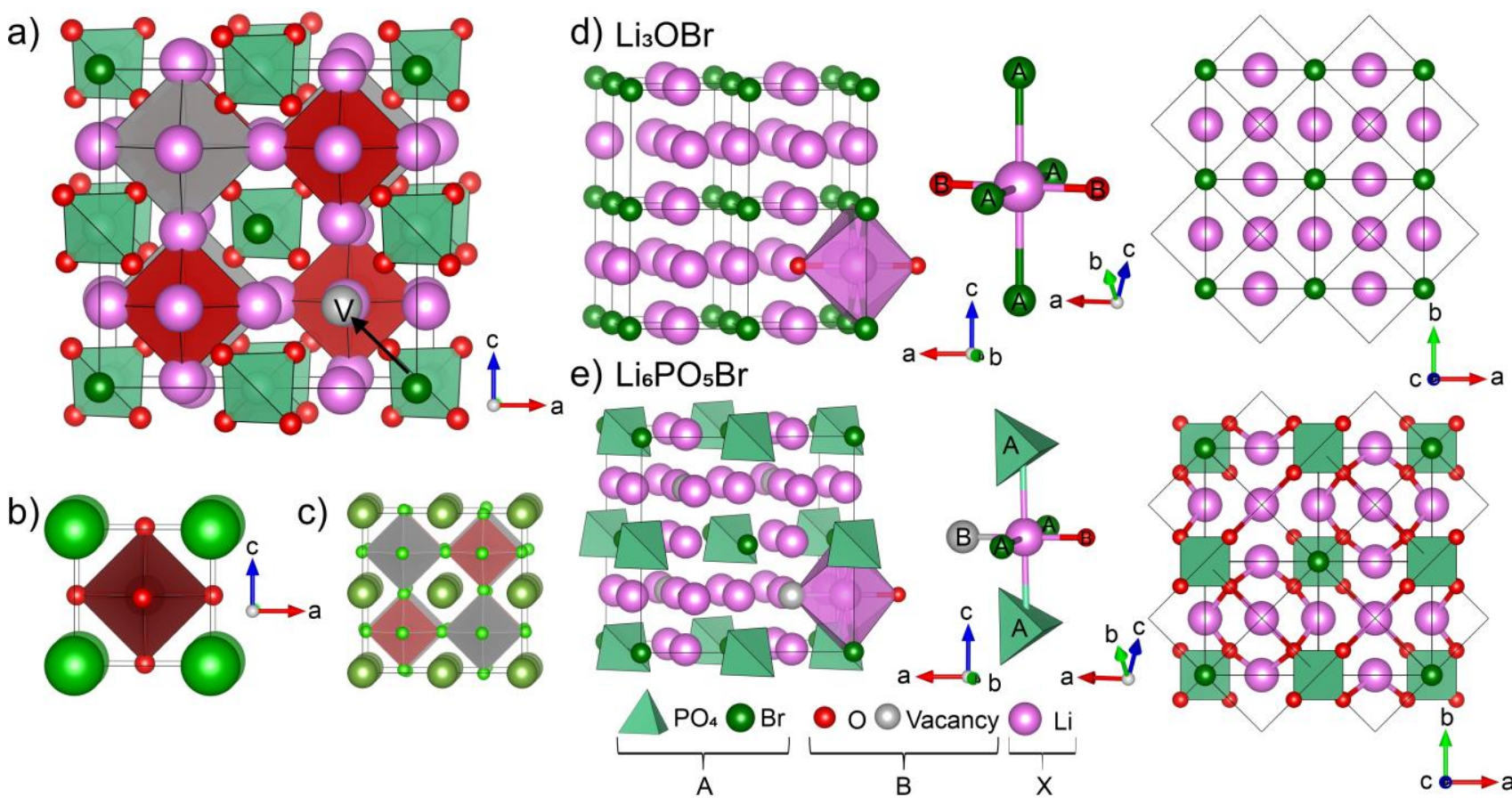
of

Figure 1. The cubic argyrodite structure of $\mathrm{Li}_{6} \mathrm{PO}_{5} \mathrm{Br}$ ( $\mathrm{Li}$ : pink, $\mathrm{P}$ : light green, $\mathrm{O}$ : red, $\mathrm{Br}$ : dark green, vacant $\mathrm{B}$-site (V): grey; the arrow shows the direction of the P-O bond vector oriented towards the vacant B-site), showing the relationship with (b) the cubic perovskite $\mathrm{SrTiO}_{3}$ (Sr: green, Ti: dark red, O:red) and (c) the B-site vacancy-ordered $\mathrm{K}_{2} \mathrm{PtCl} 6$ (K: dark green, Pt: red, Cl: light green, Vacancies: grey). d) The cubic anti-perovskite structure of $\mathrm{Li}_{3} \mathrm{OBr}$, highlighting the octahedral coordination environment of $\mathrm{Li}$, coordinated by $4 \mathrm{~A}$-site (Br: dark green) and two $\mathrm{B}$-site (O: red) anions. e) Compared with $\mathrm{Li}_{3} \mathrm{OBr}$, the cubic argyrodite structure of $\mathrm{Li}_{6} \mathrm{PO}_{5} \mathrm{Br}$ has a reduced $\mathrm{Li}$ coordination number defined by $4 \mathrm{~A}$-site ( $\mathrm{Br}$ : dark green, $\mathrm{PO}_{4}$ : polyanion light green) and one B-site anion (O: red) with half of the B-sites vacant (Vacancy: grey).

Although closely related in composition to argyrodite, the compound $\mathrm{Cu}_{8} \mathrm{GeSe}_{6}$ has a hexagonal $\mathrm{P}_{3}{ }_{3} m c$ hightemperature polymorph rather than the cubic $F \overline{4} 3 \mathrm{~m}$ argyrodite structure, ${ }^{39-41}$ as do the compounds $\mathrm{Ag}_{5} \mathrm{PS}_{4} \mathrm{I}_{2}{ }^{42}$ and $\mathrm{Li}_{8} \mathrm{SiO}_{6}{ }^{43}$ Analysis of these structures show that they contain similar close-packed layers to those present in the cubic anti-perovskite description of the argyrodite family, but that, instead of a -c- (-a-b-c-) close-packed stacking, they are stacked in a -h-c-h-c- (-a-b-a-c-) manner, as would occur in a hexagonal anti-perovskite. Different closepacked layer stacking motifs are known within the anti-perovskites. ${ }^{44}$ The argyrodite/cubic anti-perovskite structural relationship suggests that $\mathrm{Li}$-containing materials based on the hexagonal, rather than cubic, anti-perovskite stacking of these layers, related to the hexagonal structures of $\mathrm{Cu}_{8} \mathrm{GeSe}_{6}$ and $\mathrm{Ag}_{5} \mathrm{PS}_{4} \mathrm{I}_{2}$, would be analogous to the lithium-containing argyrodites, where the number of Li sites and extent of Li ordering among them control ionic conductivity.

Starting from the cubic $\mathrm{Li}_{6} \mathrm{PO}_{5} X(X=\mathrm{Cl}, \mathrm{Br})$ argyrodites, the phosphate $\left(\mathrm{PO}_{4}\right)^{3-}(\mathrm{P}-\mathrm{O}$ bond length: $1.54 \AA)$ was replaced with silicate $\left(\mathrm{SiO}_{4}\right)^{4-}(\mathrm{Si}-\mathrm{O}$ bond length: $1.65 \AA$ ) to increase the $\mathrm{A}$-site cation radius and thus drive a cubic to hexagonal transition through the perovskite tolerance factor $\left(r_{\mathrm{P}(\mathrm{V})}=0.17 \AA, r_{\mathrm{s} i(\mathrm{~V})}=0.26 \AA\right) .{ }^{45}$ The isolated oxide ion was replaced by a halide ion $(\mathrm{F}, \mathrm{Cl}, \mathrm{Br}, \mathrm{I})$ to balance charge. Structures were built with compositions $\mathrm{Li}_{6} \mathrm{SiO}_{4} X X^{\prime}$ $\left(X, X^{\prime}=\mathrm{F}, \mathrm{Cl}, \mathrm{Br}, \mathrm{I}\right)$ with the h-c-h-c- (a-b-a-c-) stacking pattern, following $\mathrm{Cu}_{8} \mathrm{GeS}_{6}$, in the $P 6_{3} m c$ space group. This affords a hexagonal anti-perovskite in which half of the A-sites are occupied with silicate polyanions and half with 
halide anions. Half of the B-sites are then occupied in an ordered manner by the remaining halide anions, with the vacant B-sites chosen to avoid interactions between the halide anions and the corners of the silicate tetrahedra (Figure 2a).
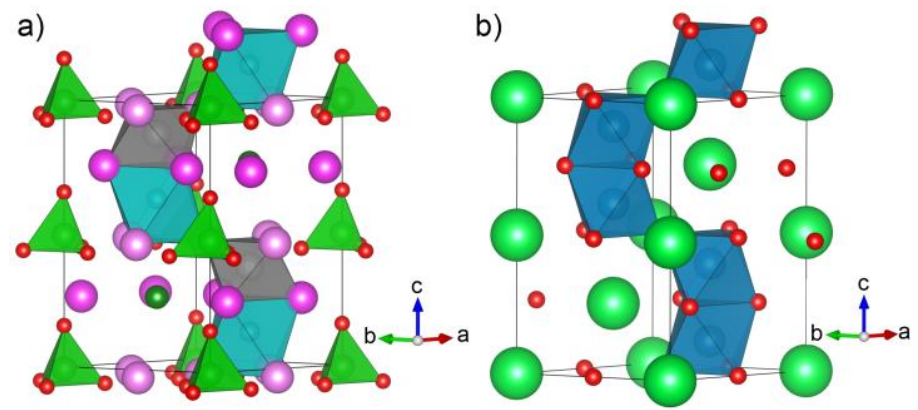

c) $\mathrm{Li}_{3} \mathrm{PO}_{4}$

d) $\mathrm{Li}_{3} \mathrm{Br}$

e) -c- stacking
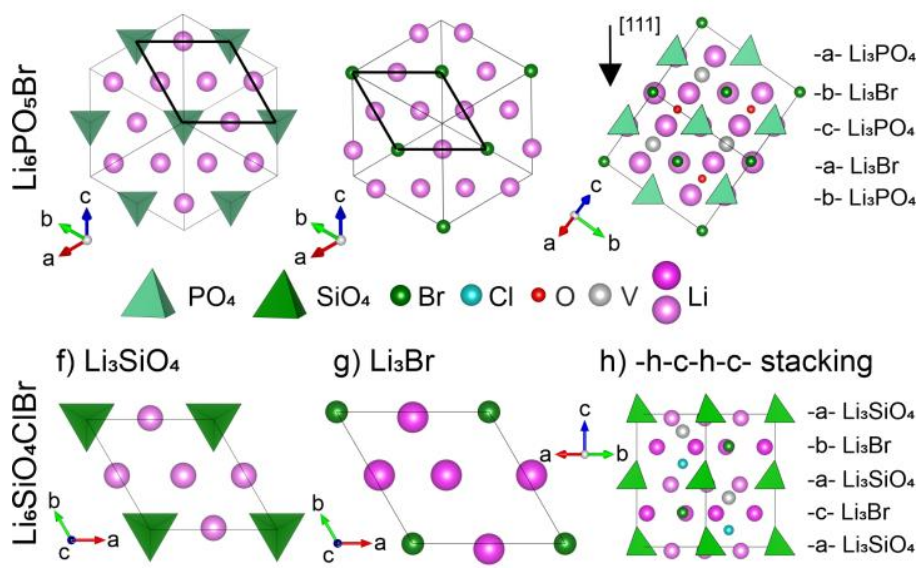

Figure 2. a) The DFT optimised $\mathrm{P}_{3}{ }_{3} m c$ structure of $\mathrm{Li}_{6} \mathrm{SiO}_{4} \mathrm{ClBr}$ ( $\mathrm{Li}$ : pink, Si: light green, O: red, Br: dark green, Cl: blue, vacant B-site: grey) is compared to (b) the $4 \mathrm{H}-\mathrm{BaMnO}_{3}$ hexagonal perovskite structure (Ba: green, $\mathrm{Mn}$ : blue, O: red). The oxide anions in the conventional hexagonal perovskite are replaced by lithium cations in $\mathrm{Li}_{6} \mathrm{SiO}_{4} \mathrm{ClBr}$, the A-site barium cations are replaced by an ordered mixture of silicate polyanions and bromide anions, and the B-site manganese cations are replaced with ordered chloride anions and vacancies. In $\mathrm{Li}_{6} \mathrm{SiO}_{4} \mathrm{ClBr}$, close-packed $\mathrm{Li}_{3} \mathrm{Br}$ layers (dark pink lithium) alternate along the $c$ direction with close-packed $\mathrm{Li}_{3} \mathrm{SiO}_{4}$ layers (light pink lithium) in an a-b-a-c- stacking sequence. Half of the octahedral B-sites between these layers are then occupied by chlorine anions (blue octahedra), leaving half of the B-sites vacant (grey octahedra). c) - h) Comparing close-packed $\mathrm{AX}_{3}$ layers in $\mathrm{Li}_{6} \mathrm{PO}_{5} \mathrm{Br}$ cubic argyrodite (viewed along the [111] direction in c and d) and computed $\mathrm{Li}_{6} \mathrm{SiO}_{4} \mathrm{ClBr}$ hexagonal argyrodite viewed along [001] in f and g: c) $\mathrm{Li}_{6} \mathrm{PO}_{5} \mathrm{Br}$ : $\mathrm{Li}_{3} \mathrm{PO}_{4}$ layer d) $\mathrm{Li}_{6} \mathrm{PO} \mathrm{O}_{5} \mathrm{Br}$ : $\mathrm{Li}_{3} \mathrm{Br}$ layer e) $\mathrm{Li}_{6} \mathrm{PO} \mathrm{Br}_{5}$ cubic (-a-b-c-) stacking of close packed $\mathrm{Li}_{3} \mathrm{Br}$ and $\mathrm{Li}_{3} \mathrm{PO}_{4}$ layers. Oxygen atoms (red) and vacancies (grey) occupy octahedral $\mathrm{B}$ - sites between the close packed layers f) $\mathrm{Li}_{6} \mathrm{SiO}_{4} \mathrm{ClBr}$ : $\mathrm{Li}_{3} \mathrm{SiO}_{4}$ layer g) $\mathrm{Li}_{6} \mathrm{SiO}_{4} \mathrm{ClBr}$ : $\mathrm{Li}_{3} \mathrm{Br}$ layer h) $\mathrm{Li}_{6} \mathrm{SiO}{ }_{4} \mathrm{ClBr}$ : -h-c-h-c (-a-ba-c) stacking of close-packed $\mathrm{Li}_{3} \mathrm{Br}$ and $\mathrm{Li}_{3} \mathrm{SiO}_{4}$ layers. Chlorine atoms (blue) and vacancies (grey) occupy octahedral B-sites between the close packed layers. For all further figures, all (poly) anions occupying the A-site are drawn in green and all B site anions are drawn in blue

This is a hexagonal analogue of the $\mathrm{Li}_{6} \mathrm{PO}_{5} \mathrm{Br}$ structure described previously, and an inverse analogue of the $4 \mathrm{H}-$ hexagonal perovskites (e.g., $4 \mathrm{H}-\mathrm{BaMnO}_{3},{ }^{46}$ stacking sequence $\mathrm{h}-\mathrm{c}-\mathrm{h}-\mathrm{c}(\mathrm{a}-\mathrm{b}-\mathrm{a}-\mathrm{c})$, Figure $2 \mathrm{~b}$ ). These hexagonal $\mathrm{Li}$ argyrodites contain similar close packed $\mathrm{AX}_{3}$ layers to the cubic argyrodites (i.e., alternating $\mathrm{Li} \mathrm{B}_{3} \mathrm{Br}$ and $\mathrm{Li}_{3} \mathrm{PO}_{4} / \mathrm{Li}_{3} \mathrm{SiO}_{4}$ layers) but they are stacked in a h-c-h-c- (a-b-a-c-) pattern and not a -c- (a-b-c-) stacking pattern (Figure 2c-2h). These compositions were then screened computationally in order to find the lower energy structures. 
Periodic DFT calculations showed that the composition $\mathrm{Li}_{6} \mathrm{SiO}_{4} \mathrm{ClBr}$ in this $P 6_{3} m c$ structure was the most stable when compared with a stoichiometric combination of lithium orthosilicate $\mathrm{Li}_{4} \mathrm{SiO}_{4}$ and the relevant binary lithium halides ( $\mathrm{LiCl}$ and $\mathrm{LiBr}$ ) (Table S1). Through phonon calculations, lower energy structures than the high symmetry hexagonal structure were found, arising from rotation of lithium atoms off the mirror plane of $P 6_{3} m c$ through activation of displacive $\Gamma_{2}, \Gamma_{3}, \Gamma_{5}, \mathrm{M}_{2}$ and $\mathrm{M}_{3}$ modes (Figure $3 \mathrm{~b}$ ), leading to four potential lower symmetry polymorphs in space groups $P 31$, $P 6_{3}, P n a 2_{1}$ and $P c a 2_{1}$. The stabilities of all compositions were re-computed in these four lower symmetry polymorphs, revealing that $\mathrm{Li}_{6} \mathrm{SiO}_{4} \mathrm{Cl}_{2}, \mathrm{Li}_{6} \mathrm{SiO}_{4} \mathrm{Br}_{2}, \mathrm{Li}_{6} \mathrm{SiO}_{4} \mathrm{ClBr}$ and $\mathrm{Li}_{6} \mathrm{SiO}_{4} \mathrm{Cll}$ were predicted to be stable (Figure 3a, Table 1, Table S1).

a)

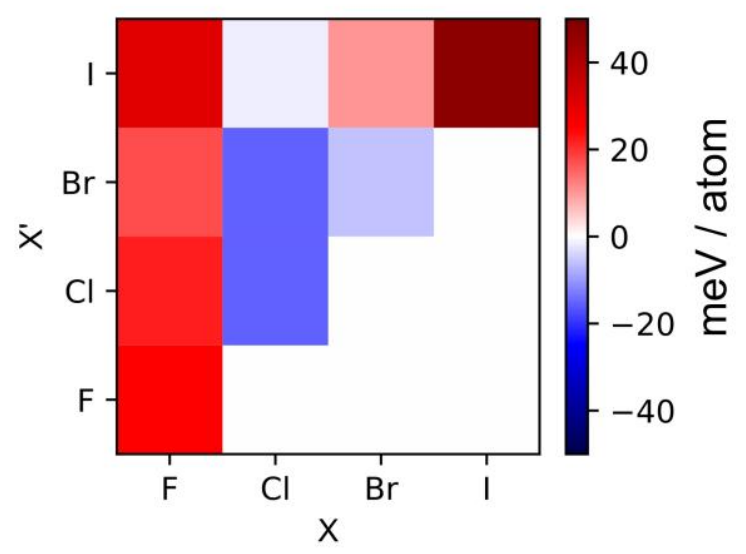

b)

b) $\quad P 31 c$

Pna21
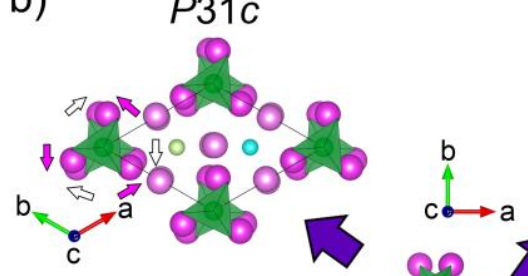

$-15 \mathrm{meV} / \mathrm{atom}$

$\Gamma_{3}$

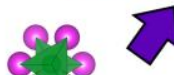

-19 meV/atom

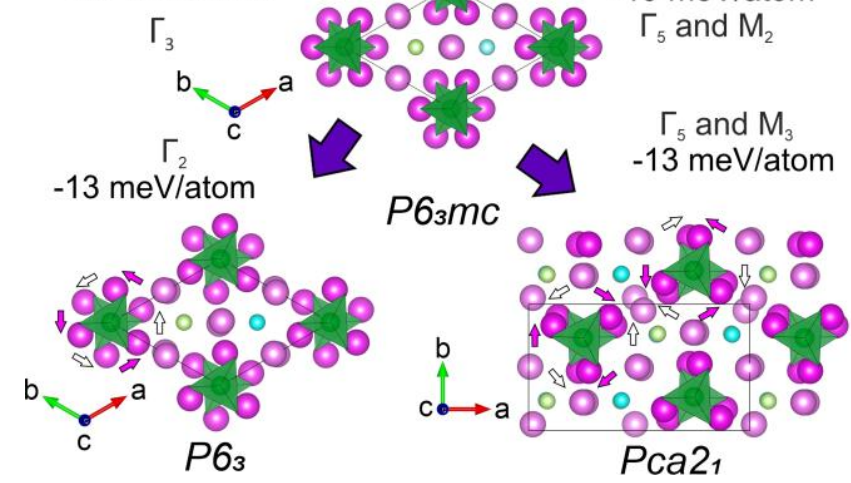

Figure 3. a) The stabilities of the compounds $\mathrm{Li}_{6} \mathrm{SiO}_{4} X X^{\prime}\left(X X X^{\prime}=\mathrm{F}^{-}, \mathrm{Cl}^{-}, \mathrm{Br}^{-}, \mathrm{I}^{-}\right)$against decomposition into $\mathrm{Li}_{4} \mathrm{SiO}_{4}+\mathrm{Li} X+\mathrm{Li} X^{\prime}$, calculated using DFT. $\mathrm{Li}_{6} \mathrm{SiO}_{4} \mathrm{BrCl}$ and $\mathrm{Li}_{6} \mathrm{SiO}_{4} \mathrm{Cl}_{2}$ are calculated to be the most stable compositions. b) DFT optimised structures of $\mathrm{Li}_{6} \mathrm{SiO}_{4} \mathrm{Cl}_{2}$ (Li: pink, $\mathrm{SiO}_{4}$ : green, $\mathrm{Cl}$ : light green and blue). In the high symmetry $\mathrm{P}_{3} m c$ structure (centre), half of the lithium ions lie on mirror planes (shown in darker pink). Displacement of these lithium ions off the mirror planes leads to a lowering of symmetry and a reduction in the DFT calculated energy. Triangles of lithium ions are displaced by small rotations about the $c$ axis. These rotations can be in phase or out of phase, leading to the different low symmetry structures shown. Rotations of lithium ions in the $\mathrm{Li}_{3} \mathrm{SiO}_{4}$ layers and $\mathrm{Li}_{3} \mathrm{Cl}$ layers are shown by pink and white arrows, respectively. 
Table 1: Computed decomposition energies of the compounds $\mathrm{Li}_{6} \mathrm{SiO}_{4} \mathrm{XX}$ ' in the most stable symmetry

\begin{tabular}{|c|c|c|}
\hline Composition & $\begin{array}{l}\text { Energy } \\
\text { mev/atom }\end{array}$ & Symmetry \\
\hline $\mathrm{Li}_{6} \mathrm{SiO}_{4} \mathrm{Cl}_{2}$ & -18 & $P n a 2_{1}$ \\
\hline $\mathrm{Li}_{6} \mathrm{SiO}_{4} \mathrm{CIBr}$ & -16 & Pna21 \\
\hline $\mathrm{Li}_{6} \mathrm{SiO}_{4} \mathrm{Br}_{2}$ & -6 & Pna21 \\
\hline $\mathrm{Li}_{6} \mathrm{SiO}_{4} \mathrm{Cll}$ & -2 & $P 6{ }_{3} m c$ \\
\hline
\end{tabular}

These results suggest that a new lithium hexagonal argyrodite family of compounds may be experimentally accessible, with $\mathrm{Li}_{6} \mathrm{SiO}_{4} \mathrm{Cl}_{2}$ and $\mathrm{Li}_{6} \mathrm{SiO}_{4} \mathrm{ClBr}$ (with the larger $\mathrm{Br}$ ordered on the $\mathrm{A}$ site) predicted to be the most stable and chosen as targets for experimental synthesis.

DFT calculations of the elastic constants of $\mathrm{Li}_{6} \mathrm{SiO}_{4} \mathrm{Cl}_{2}$ in the $P n a 2_{1}$ structure result in a computed bulk modulus, $B_{D F T}$, of $53 \mathrm{GPa}$ and a computed shear modulus, $G_{D F T}$, of $31 \mathrm{GPa}$. This material is considerably softer than oxide solid state lithium electrolytes such as $\mathrm{Li}_{7} \mathrm{La}_{3} \mathrm{Zr}_{2} \mathrm{O}_{12}\left(B_{D F T}=117 \mathrm{GPa}, \mathrm{G}_{D F T}=64 \mathrm{GPa}\right),{ }^{19}$ and has mechanical properties closer to that of the lithium anti-perovskites (e.g., $\mathrm{Li}_{3} \mathrm{OBr}, B_{D F T}=50.6 \mathrm{GPa}, \mathrm{G}_{D F T}=37 \mathrm{GPa}$ ). $\mathrm{Li}_{6} \mathrm{SiO}_{4} \mathrm{Cl}_{2}$ is stiffer than related sulphide compounds (e.g. $\mathrm{Li}_{6} \mathrm{PS}{ }_{5} \mathrm{Br}$ : $B_{D F T}=27 \mathrm{GPa}, \mathrm{G}_{D F T}=14 \mathrm{GPa}$ ) and consequently easily meets the Monroe-Newman criterion for the prevention of dendrite growth. ${ }^{47}$ Future electrolytes based on these mixed oxide/halide compounds may thus be able to overcome some of the processing challenges and mechanical stability issues inherent in the use of pure oxide and sulphide ceramics. ${ }^{48}$

\subsection{Synthesis, thermal behaviour and structure determination}

Compounds were synthesised as powders with compositions $\mathrm{Li}_{6} \mathrm{SiO}_{4} \mathrm{Cl}_{2-x} \mathrm{Br}_{\mathrm{x}}(\mathrm{x}=0,0.5,1)$ to explore the computationally predicted targets. Synthesis of powders was attempted at varying reaction temperatures $(50 \mathrm{~K}$ steps from $723 \mathrm{~K}$ to $873 \mathrm{~K}$ ) and reaction times (12 h, 24h, 48h), and starting materials and resulting powders were handled under argon atmosphere and annealed in alumina crucibles in evacuated silica ampoules (Section 3.2). Synthesis at $823 \mathrm{~K}$ for $48 \mathrm{~h}$ yielded phase pure powders for $\mathrm{Li}_{6} \mathrm{SiO}_{4} \mathrm{Cl}_{2}$. This new phase persists in the compositional range $\mathrm{Li}_{6} \mathrm{SiO}_{4} \mathrm{Cl}_{2-x} \mathrm{Br}_{x}(0 \geq x \geq 1)$ and displays increased lattice parameters as a function of bromine content (Figure S1). Despite this clear indication of anion substitution all compositions with $x>0$ contained impurities; only $\mathrm{Li}_{6} \mathrm{SiO}_{4} \mathrm{Cl}_{2}$ was synthesised as a phase pure white powder, and as such all further discussion therefore concerns $\mathrm{Li}_{6} \mathrm{SiO}_{4} \mathrm{Cl}_{2}$. Single crystals of $\mathrm{Li}_{6} \mathrm{SiO}_{4} \mathrm{Cl}_{2}$ were synthesised by annealing at $883 \mathrm{~K}$ for $3 \mathrm{~h}$ before slow cooling $(3 \mathrm{~K} \mathrm{~h}$ 1) to room temperature. High resolution synchrotron XRD data (SXRD) were collected on the powder from $298 \mathrm{~K}$ to $798 \mathrm{~K}$ in $25 \mathrm{~K}$ steps. At temperatures $473-498 \mathrm{~K}$, convergence of some peaks and disappearance of other small peaks indicates a phase transition to a high temperature, higher symmetry phase (denoted HT-phase) (Figure 4a, 4b). This transition is also observed in differential scanning calorimetry (DSC) data measured from $\mathrm{Li}_{6} \mathrm{SiO}_{4} \mathrm{Cl}_{2}$ powder, which shows endothermic and exothermic events on heating and cooling, respectively, associated with this reversible phase transition (Figure 4c). The exact transition temperature determined from DSC data is 469.3(1) $\mathrm{K}$, consistent with the observations from SXRD, NMR and AC impedance measurements (see below). Similarly to the RT-phase, the experimental SXRD pattern of the HT-phase could not be indexed to any known compounds in the $\mathrm{Li}-\mathrm{Si}-\mathrm{O}-\mathrm{Cl}$ phase field. The structure of the RT-phase was solved by single crystal (SC) X-ray diffraction, and the HT-phase by Rietveld refinement of a computed starting model against high resolution SXRD data. 

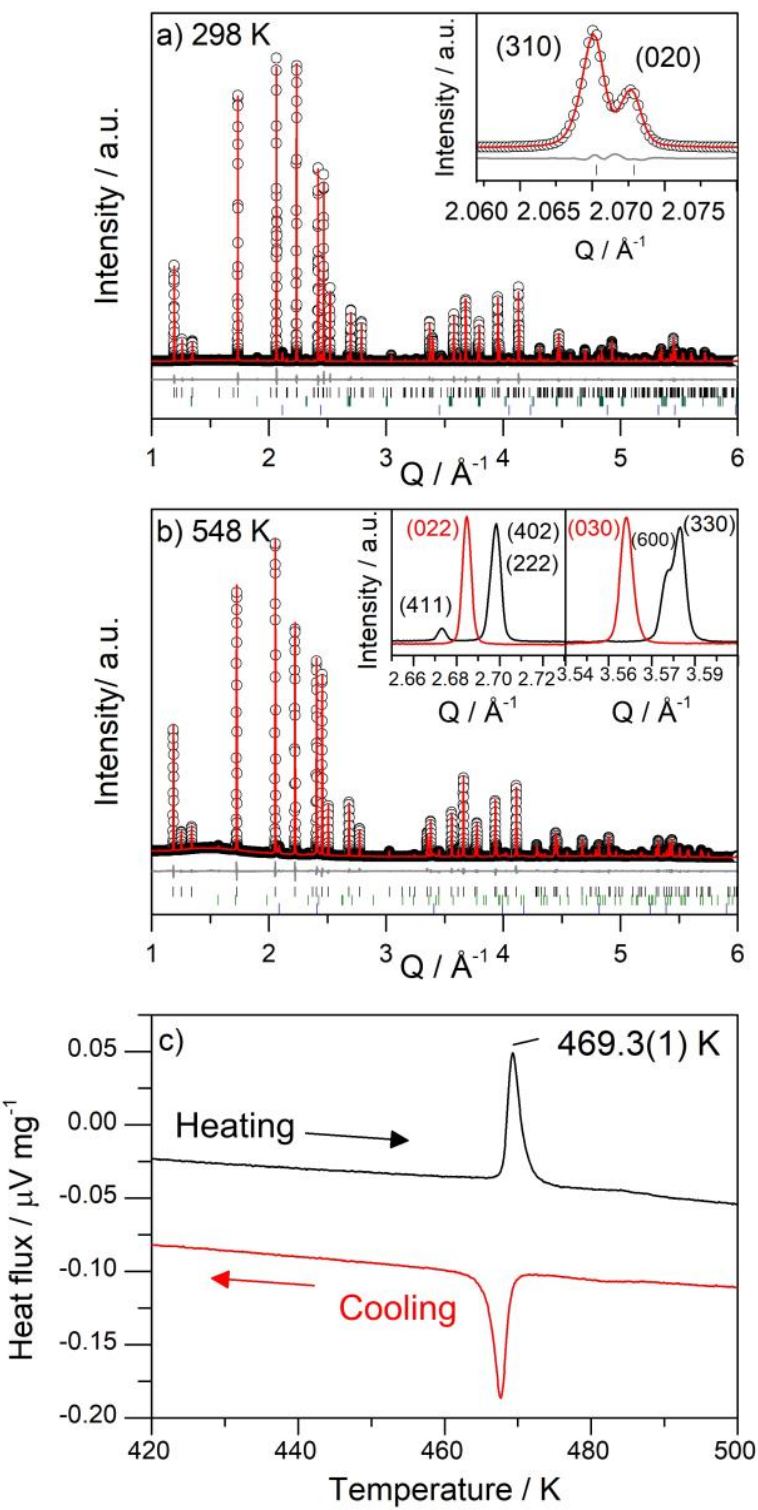

Figure 4. a) $\mathrm{RT}-\mathrm{Li}_{6} \mathrm{SiO}_{4} \mathrm{Cl}_{2}$ : Rietveld refinement against SXRD of $\mathrm{RT}-\mathrm{Li}_{6} \mathrm{SiO}_{4} \mathrm{Cl}_{2}$ (Diamond Light Source 111 beam line) with lobs (black circles), Icalc (red line), lobs - Icalc (grey line) and Bragg reflections (black tick marks for $\mathrm{Li}_{6} \mathrm{SiO}_{4} \mathrm{Cl}_{2}$, green tick marks for $\mathrm{Li}_{2} \mathrm{SiO}_{3}$, blue tick marks for $\mathrm{LiCl}$ ), inset highlights reflections consistent with orthorhombic Pna2 ${ }_{1}$ symmetry. b) $\mathrm{HT}-\mathrm{Li}_{6} \mathrm{SiO}_{4} \mathrm{Cl}_{2}$ : Rietveld refinement against SXRD data of $\mathrm{Li}_{6} \mathrm{SiO}_{4} \mathrm{Cl}_{2}$ (black tick marks for $\mathrm{Li}_{6} \mathrm{SiO}_{4} \mathrm{Cl}_{2}$, green tick marks for $\mathrm{LiAlO}_{2}$ and blue tick marks for $\mathrm{LiCl}$ ), inset compares reflections from RT orthorhombic phase at $298 \mathrm{~K}$ (black line) with the HT hexagonal phase at $548 \mathrm{~K}$ (red line) c) Differential scanning calorimetry (DSC) data showing a reversible thermal event associated with phase transition between $P \mathrm{Pna}_{1}$ and $\mathrm{P}_{3}{ }_{3} \mathrm{mc}$ symmetry in $\mathrm{Li}_{6} \mathrm{SiO}_{4} \mathrm{Cl}_{2}$

\subsubsection{Room temperature phase - Structure Determination}

The crystal structure was solved in space group Pna21 from a non-merohedrally twinned crystal with lattice parameters: $a=10.5204(8) \AA, b=6.0756(4) \AA, c=9.9530(7) \AA$. The assignments of $\mathrm{Li}, \mathrm{Si}, \mathrm{O}$, and $\mathrm{Cl}$ were determined based on interatomic distances and relative displacement parameters. All atomic positions were refined with fixed fully occupied sites. Lithium atoms exhibited non-positive definite anisotropic mean square displacements, so ISOR restraints were applied to atoms Li1 -6 during the final refinement, and also to atoms $\mathrm{O} 2-4$ as a result of distorted thermal ellipsoids. Final anisotropic atomic refinement converged to $R_{1}=0.0530, w R_{2}=0.1189$ for reflections with $\mathrm{I} \geq 2 \sigma(\mathrm{I})$ and $\mathrm{R}_{1}=0.0750, \mathrm{wR}_{2}=0.1279$ for all reflections. Crystallographic data and structural refinements for $\mathrm{Li}_{6} \mathrm{SiO}_{4} \mathrm{Cl}_{2}$ are summarized in Table S2. The asymmetric unit contains two distinct crystallographic 
$\mathrm{Cl}$ positions, four distinct $\mathrm{O}$ positions, one Si position (further confirmed by ${ }^{29} \mathrm{Si}$ solid-state NMR which displays a main signal at $-67 \mathrm{ppm}$, Figure S2, corresponding to a $\mathrm{SiO}_{4}{ }^{4-}$ unit) and six Li positions. The final refined atomic positions, isotropic and anisotropic displacement parameters of each atom are given in Tables S3 and S4, and selected bond lengths and angles in Tables S5 and S6. Orthorhombic superlattice reflections characteristic of Pna2 1 (e.g., (411)) symmetry are clearly visible in the diffraction image, ruling out possible C-centred orthorhombic or hexagonal (as $a \approx \sqrt{3} b$ ) supergroups.

The high-resolution room temperature SXRD data further confirms this model showing subtle peak splitting consistent with Pna2 1 symmetry (Figure 4a inset) evident due to higher $Q$ resolution in the synchrotron data.

The observed systematic absences in the SXRD data were consistent with the Pna2 ${ }_{1}$ space group and the lattice parameters refined to $a=10.543155(5) \AA, b=6.07657(3) \AA, c=9.960255(5) \AA$ from a Pawley fit. The model obtained from SC diffraction proved to be a good starting point for Rietveld refinement with values of $R_{w p}=4.61$ and $\chi^{2}=2.81$ after initial refinement of site occupancies and displacement parameters. $\mathrm{Cl}$ and $\mathrm{O}$ site occupancies were refined and $\mathrm{Li}$ site occupancies were fixed to achieve charge neutrality. Refinement of atomic positions improved $R_{w p}$ from 4.61 to 4.27 and $\chi^{2}$ from 2.81 to 2.61 (Figure S3). Small impurity phases of LiCl (1.95\%) and $\mathrm{Li}_{2} \mathrm{SiO}_{3}(2.35 \%)$ were observed (Figure S4a). Maximum entropy method (MEM) analysis did not show any additional electron density, indicating that all lithium sites are accounted for in the structural model described above (Figure S6). The final Rietveld fit is shown in Figure 4a and refined structural parameters are presented in Tables $\mathrm{S} 7$ and S8. The refined composition is $\mathrm{Li}_{5.957(2)} \mathrm{Si}_{1.00} \mathrm{O}_{3.986(2)} \mathrm{Cl}_{1.985(1)}$ and the RT-phase will therefore be denoted RT$\mathrm{Li}_{6} \mathrm{SiO}_{4} \mathrm{Cl}_{2}$ hereafter for simplicity.

\subsubsection{Room temperature phase - Structure Description}

As described in Section 4.1, the orthorhombic structure arises from rotation of lithium atoms off the mirror plane in $P 6_{3} m c$ through activation of $\Gamma_{5}$ and $M_{2}$ modes, stabilising the Pna2 1 symmetry. This leads to a change in anionic and cationic coordination environments compared to the hexagonal defect anti-perovskite parent.

The experimentally-determined RT structure is shown in Figure $5 \mathrm{a}$, highlighting the atomic packing within the structure defined by alternating $\mathrm{Li}_{3} \mathrm{SiO}_{4}$ and $\mathrm{Li}_{3} \mathrm{Cl}$ layers. Comparison of the experimentally determined Pna2 1 structure to the computed structure shows almost identical atomic positions (Figure S7a). The chloride ions that occupy $50 \%$ of the anti-perovskite B-site positions ( $\mathrm{Cl} 1$ ) are found in an octahedral environment with bond lengths ranging from 2.415(3) $\AA$ to $2.621(3) \AA$ to neighbouring Li. Compared to the idealised octahedral environment expected for B-site anions in anti-perovskites, the octahedra are distorted slightly as a result of the non-rigid rotation of $\mathrm{Li}$ ions and the displacement of chlorine towards neighbouring vacant $\mathrm{B}$-sites. The chloride ions that occupy $50 \%$ of the A site (Cl2), typically forming cuboctahedral (12-fold) coordination environments in hexagonal perovskites such as $4 \mathrm{H}-\mathrm{BaMnO}_{3}$, occupy a distorted octahedral environment in the orthorhombic polymorph with bond lengths from 2.446(3) $\AA$ to 2.798(7) (Figure S8). All lithium atoms are found in tetrahedral $\mathrm{LiCl}_{2} \mathrm{O}_{2}$ coordination environments. Due to the difference in ionic radii $\left(r_{\mathrm{Cl}}=1.81 \AA\right.$, $\left.r_{\mathrm{O}}=1.40 \AA\right),{ }^{45}$ lithium atoms are displaced towards the oxygen atoms (Figure $5 \mathrm{c}$ ). Li-O bond lengths vary from 1.829(3) $\AA$ to $1.931(3) \AA$, comparable to distances reported for the cubic argyrodite $\mathrm{Li}_{6} \mathrm{PO}_{5} \mathrm{Cl}(1.93 \AA)^{9}$ and shorter than $\mathrm{Li}-\mathrm{O}$ bonds in $\mathrm{Li}_{4} \mathrm{SiO}_{4}$ $(1.84-2.51 \AA) .{ }^{49} \mathrm{Li}-\mathrm{Cl}$ bond lengths range from 2.415(3) $\AA$ to $2.798(3) \AA$. . These values are larger than expected for typical $\mathrm{LiCl}_{4}$ bond lengths, e.g., $2.38 \AA$ in $\mathrm{Li}_{2} \mathrm{MgCl}_{4} .{ }^{50}$ The difference in bond lengths compared to homoleptic $\mathrm{LiCl}_{4}$ and $\mathrm{LiO}_{4}$ tetrahedral environments is expected in heteroleptic $\mathrm{LiCl}_{2} \mathrm{O}_{2}$ and optimizes the bond valence sum for $\mathrm{Li}^{+}$(BVS: $\left.0.939(8)-1.12(1)\right)$. The $\mathrm{Li}-\mathrm{Cl}$ distances in $\mathrm{Li}_{6} \mathrm{SiO}_{4} \mathrm{Cl}_{2}$ are shorter than in the cubic oxide argyrodite 
$\mathrm{Li}_{6} \mathrm{PO}_{5} \mathrm{Cl}(2.910(4) \AA)$, in which $\mathrm{Li}$ atoms have trigonal bipyramidal coordination $\left(\mathrm{LiO}_{3} \mathrm{Cl}_{2}\right)$ with $\mathrm{Cl}$ occupying the axial positions. ${ }^{9}$

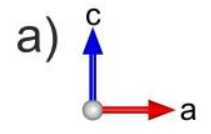

$-\mathrm{a}-\mathrm{Li}_{3} \mathrm{SiO}_{4}$

$-\mathrm{b}-\mathrm{Li}_{3} \mathrm{Cl}$

-a- $\mathrm{Li}_{3} \mathrm{SiO}_{4}$

$-\mathrm{C}-\mathrm{Li}_{3} \mathrm{Cl}$

-a- $\mathrm{Li}_{3} \mathrm{SiO}_{4}$

c)

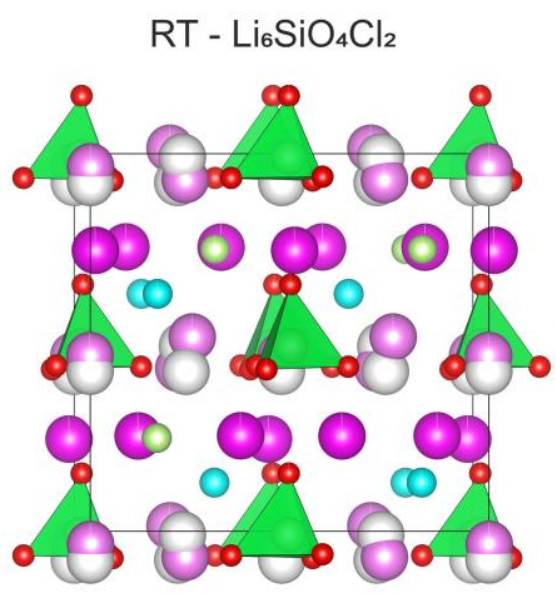

$\mathrm{Cl} 2$

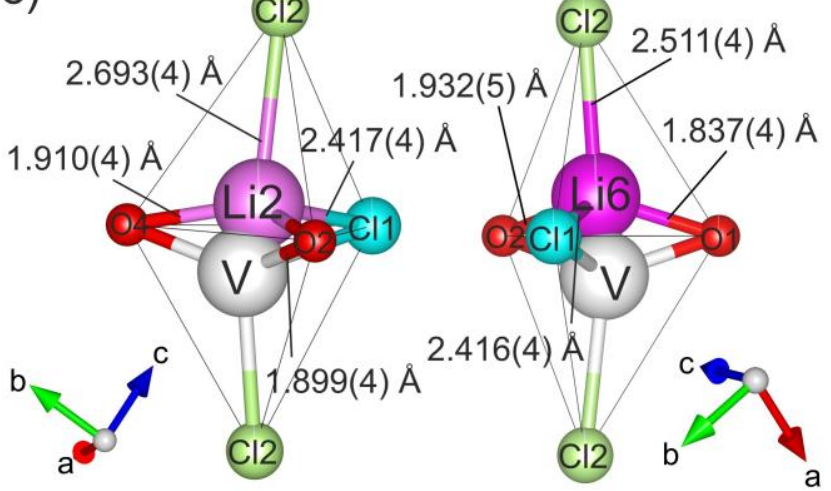

b)<smiles>[2H][C@H](C)[C@H](C)C(C)C</smiles>

$\mathrm{HT}-\mathrm{Li}_{6} \mathrm{SiO}_{4} \mathrm{Cl}_{2}$

$\mathrm{Li} \quad-\mathrm{a}-\mathrm{Li}_{3} \mathrm{SiO}_{4}$

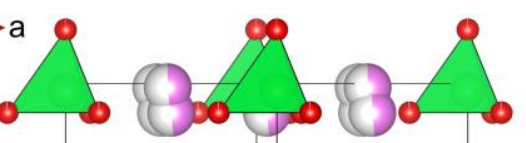

$-b-\mathrm{Li}_{3} \mathrm{Cl}$

-a- $\mathrm{Li}_{3} \mathrm{SiO}_{4}$

-C- $\mathrm{Li}_{3} \mathrm{Cl}$

-a- $\mathrm{Li}_{3} \mathrm{SiO}_{4}$

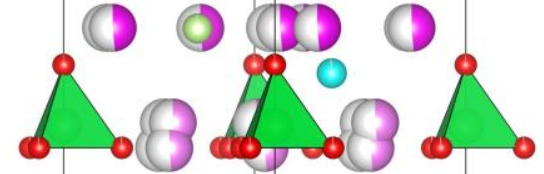

- $\mathrm{Cl}$

- Cl

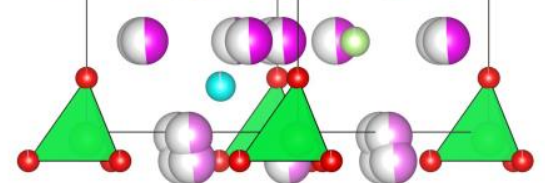

d)

Cl2

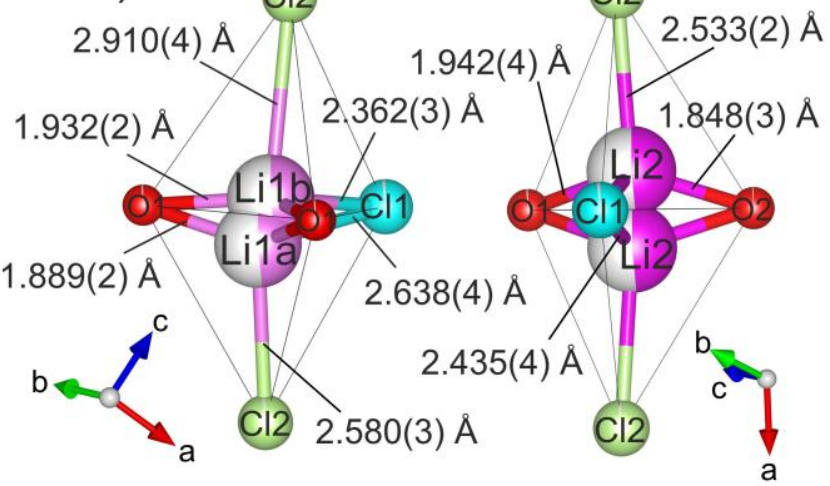

e)

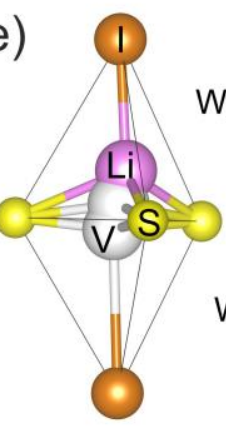

$\mathrm{LT}-\mathrm{Li}_{6} \mathrm{PS} \mathrm{S}_{5}$

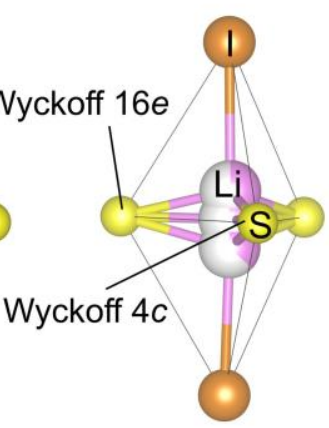

$\mathrm{HT}-\mathrm{Li}_{6} \mathrm{PS} \mathrm{S}_{5}$
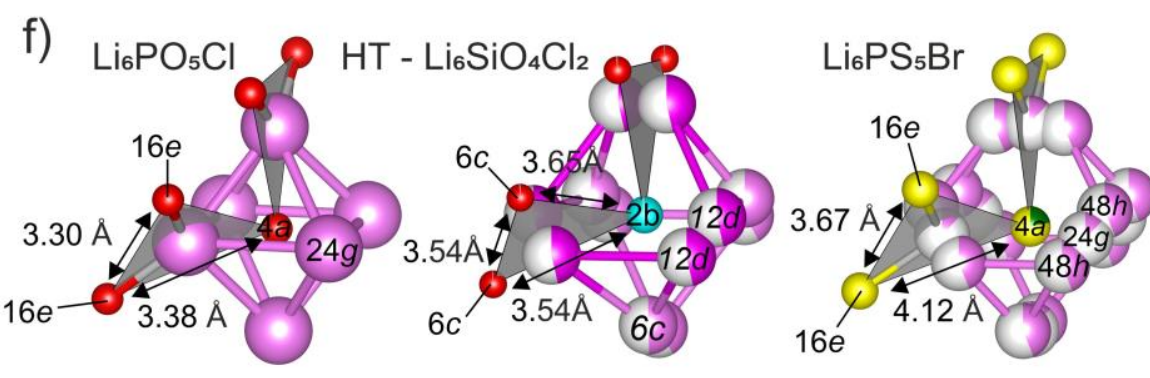

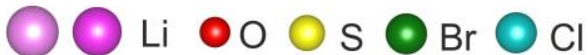

Figure 5. a) $\mathrm{RT}-\mathrm{Li}_{6} \mathrm{SiO}_{4} \mathrm{Cl}_{2}$ unit cell showing alternating $\mathrm{Li}_{3} \mathrm{Cl}$ and $\mathrm{Li}_{3} \mathrm{SiO}_{4}$ layers. Comparing with $\mathrm{ABX}_{3}$ perovskite, $\mathrm{SiO}_{4}$ (green tetrahedra) and $\mathrm{Cl} 2$ (light green) occupy the A- sites, Cl1 (blue) ions fill 50\% of the B-sites with remaining 50\% vacant, Lithium atoms occupy the X-sites (Li1, Li2, Li3 atoms in light pink, Li4, Li5, Li6 atoms in dark pink). Vacant tetrahedral lithium sites in the $\mathrm{Li}_{3} \mathrm{SiO}_{4}$ layer are shown in white to facilitate comparison with the $\mathrm{HT}$-structure. b) $\mathrm{HT}-\mathrm{Li}_{6} \mathrm{SiO}_{4} \mathrm{Cl}_{2}$ unit cell showing the same alternating $\mathrm{Li}_{3} \mathrm{Cl}$ and $\mathrm{Li}_{3} \mathrm{SiO}_{4}$ layers. Lithium atoms are disordered over partially occupied sites with respect to the RT-structure ( $\mathrm{Li} 1 \mathrm{a}$ and $\mathrm{Li1b}$ atoms in light pink, $\mathrm{Li} 2$ atoms in dark pink). c) $\mathrm{RT}-\mathrm{Li}_{6} \mathrm{SiO}_{4} \mathrm{Cl}_{2}$ lithium tetrahedra showing displacement of lithium (4a Wyckoff site) towards coordinating oxygen. The vacant tetrahedral sites (V), drawn in white, are generated by activation of occupational modes when lowering the symmetry of $\mathrm{HT}-\mathrm{Li}_{6} \mathrm{SiO}_{4} \mathrm{Cl}_{2}$ to Pna2 ${ }_{1}$ through ISODISTORT (Figure S10). d) HT $\mathrm{Li}_{6} \mathrm{SiO}_{4} \mathrm{Cl}_{2} \mathrm{Li1a}$, Li1b (6c Wyckoff site) and Li2 (12d Wyckoff site) coordination environment, showing partial occupancy of tetrahedral sites that are both fully occupied and vacant at RT. e) This order-disorder behaviour of lithium sites is analogous to 
the lithium distribution in $\mathrm{Li}_{6} \mathrm{PS}_{5} \mathrm{l}$ argyrodite; ${ }^{21}$ at low temperatures (LT) lithium atoms are ordered occupying one of the tetrahedral positions, whereas at high temperature (HT) lithium ions are disordered with partial occupancy of tetrahedral and trigonal positions. Distinct sulphide anion positions are labelled in the HT-structure. f) Octahedral Li-ion cages surrounding Bsite anions in $\mathrm{Li}_{6} \mathrm{PO}_{5} \mathrm{Cl}$ (cubic), $\mathrm{HT}-\mathrm{Li}_{6} \mathrm{SiO}_{4} \mathrm{Cl}_{2}$ (hexagonal) and $\mathrm{Li}_{6} \mathrm{PS} 55$ Br (cubic). Trigonal anion windows (consisting of three oxide anions in $\mathrm{Li}_{6} \mathrm{PO}_{5} \mathrm{Cl}$, two oxide anions and one chloride anion in $\mathrm{Li}_{6} \mathrm{SiO}_{4} \mathrm{Cl}_{2}$, and two sulphide and one mixed sulphide/bromide site in $\mathrm{Li}_{6} \mathrm{PS}{ }_{5} \mathrm{Br}$ ) are shown, highlighting their anion-anion distances which determine window area. Two distinct trigonal windows are present in $\mathrm{HT}-\mathrm{Li}_{6} \mathrm{SiO}_{4} \mathrm{Cl}_{2}$, with oxide ions either both occupying Wyckoff position $6 c$ (edge length: $3.54 \AA$ ) or occupying Wyckoff positions $2 a$ and $6 c$ (edge length: $3.23 \AA$ ). Lithium ions move through these windows in argyrodite solid electrolytes.

In the RT-structure, $\mathrm{LiCl}_{2} \mathrm{O}_{2}$ tetrahedra are connected through the corner-sharing of $\mathrm{Cl}$ and $\mathrm{O}$ vertices, and the sharing of $\mathrm{Cl}-\mathrm{Cl}$ edges; they are referred to using the central lithium atom, i.e., $\mathrm{Li}(1) \mathrm{O}_{2} \mathrm{Cl}_{2}$ as a $\mathrm{Li} 1$ tetrahedron. Edge-sharing between Li1-Li3 and Li4-Li6 tetrahedra is facilitated by the lithium ion displacements away from the shared $\mathrm{Cl}-\mathrm{Cl}$ edges (Figure $6 \mathrm{a}$ and $6 \mathrm{c}$ ), minimising electrostatic repulsions.

The $\mathrm{Li}_{3} \mathrm{SiO}_{4}$ layer can be described (Figure 6a) as alternating corner-sharing $\mathrm{Li} 2-\mathrm{Li} 3$ and $\mathrm{Li}_{1}-\mathrm{SiO}_{4}$ chains running along $\mathrm{b}$, connected in the a-direction by $\mathrm{Li} 1$ - $\mathrm{Li} 2, \mathrm{SiO}_{4}-\mathrm{Li} 2, \mathrm{SiO}_{4}-\mathrm{Li} 3$ corner-sharing and $\mathrm{Li} 1-\mathrm{Li} 3$ edge-sharing (Figure $6 \mathrm{~b}$ and $6 \mathrm{c}$ ). $\mathrm{Cl} 2$ atoms located in the $\mathrm{Li}_{3} \mathrm{Cl}$ layers connect $\mathrm{Li}_{3} \mathrm{SiO}_{4}$ layers along the stacking c-direction (Figure 6b). The $\mathrm{Li}_{3} \mathrm{Cl}$ layer is made up of $\mathrm{Li} 4$, $\mathrm{Li} 5$ and $\mathrm{Li} 6$ tetrahedra connected through Li4-Li5, Li4-Li6, Li5-Li6 corner-sharing and $\mathrm{Li} 4-\mathrm{Li} 6$ edge-sharing (Figure $6 \mathrm{c}$ and $6 \mathrm{~d}$ ). The $\mathrm{Li}_{3} \mathrm{Cl}$ layer is connected to the $\mathrm{Li}_{3} \mathrm{SiO}_{4}$ layer through cornersharing with $\mathrm{Li} 1, \mathrm{Li} 2, \mathrm{Li} 3$ and $\mathrm{SiO}_{4}$ tetrahedra, forming the 3D-network of corner- and edge-shared tetrahedra.

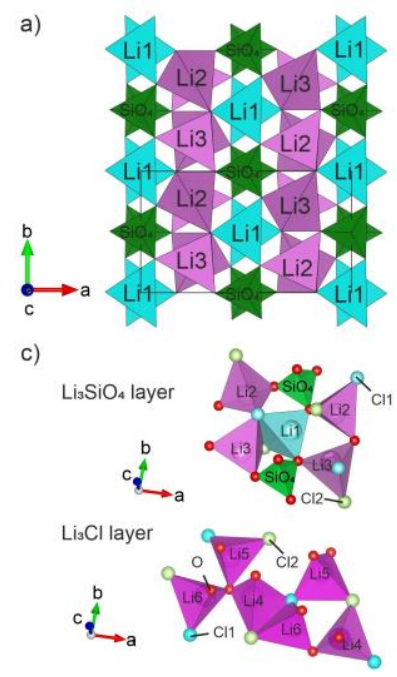

b)

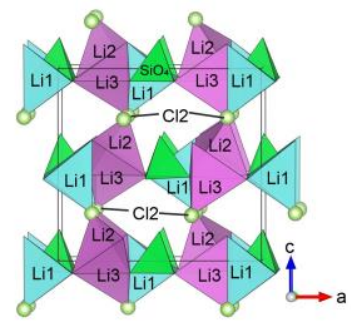

d)

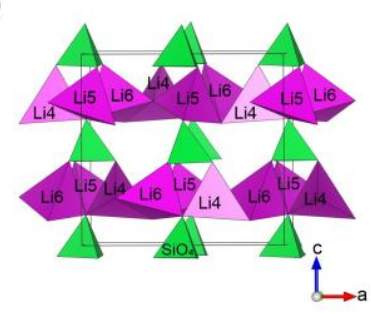

Figure 6. a) $\mathrm{Li}_{3} \mathrm{SiO}_{4}$ intralayer environments, $\mathrm{Li} 2-\mathrm{Li} 3$ (pink) and $\mathrm{Li}_{1}-\mathrm{SiO}_{4}$ (blue and green respectively) chains of corner- and edge-sharing tetrahedra b) Connection of $\mathrm{Li}_{3} \mathrm{SiO}_{4}$ layers along the stacking axis $(c)$ through corner sharing of $\mathrm{Cl} 2$ atoms (light green). c) $\mathrm{Li}_{3} \mathrm{SiO}_{4}$ (top) and $\mathrm{Li}_{3} \mathrm{Cl}$ (bottom) layers consisting of corner- and edge-sharing tetrahedra (Li1: light blue Li2, Li3: light pink, Li4, Li5, Li6: dark pink Si: green, $\mathrm{Cl} 1$ (B sites): blue, $\mathrm{Cl} 2$ (A sites): light green, O: red), all shared edges are $\mathrm{Cl}-\mathrm{Cl}$. d) $\mathrm{Li}_{3} \mathrm{Cl}$ layers connected via $\mathrm{SiO}_{4}$ units viewed along the b-direction showing stacking along $c, \mathrm{SiO}_{4}$ tetrahedra are shown to guide the eye. 


\subsubsection{High temperature phase - Structure determination}

Indexing of the HT phase (above $523 \mathrm{~K}$ ) with TOPAS resulted in a hexagonal unit cell with lattice parameters $a=$ $6.11 \AA$ and $c=10.02 \AA$. Systematic absences in the powder pattern were consistent with the $P 31 c$ and $P 6_{3} m c$ space groups, agreeing with the computationally-stable hexagonal structures (Section 4.1, Figure 3c). Very similar Pawley fits were obtained using these symmetries, and lattice parameters refined to $a=6.110805(12) \AA$ and $c=$ 10.02068(3) A for $P 6_{3} m c$ (Figure S4b). The higher symmetry computed $P 6_{3} m c$ structure gave a reasonable starting point for Rietveld refinement. The unit cell contains two distinct crystallographic Cl positions (Wyckoff position $2 b$ ), two O positions (Wyckoff positions $6 c$ and 2a), one Si position (Wyckoff position 2a) and three Li positions (Wyckoff positions $6 c$ and 12d). Occupancies of $\mathrm{Cl}$ and $\mathrm{O}$ sites were refined and the occupancies of Li sites were fixed to ensure charge neutrality. In the computational model, Li2 is located on the mirror plane in special position $6 c$ (Figure S7b). Inspection of the Fourier Density Map (FDM) reveals extra electron density around this position and indicates displacement of Li2 away from the mirror plane onto the general position 12d (Figure S9a). Replacing the $6 c$ site with the $12 d$ position improved $R_{w p}$ from 3.61 to $2.98 \%$. The FDM also revealed electron density around the Li1 position along the c-direction (Figure S9b). Splitting the Li1 site into two distinct Li1a and Li1b sites along c further improved $R_{w p}$ to $2.75 \%$. The computed P31C model (Figure 3c) is similar, only allowing two distinct $6 \mathrm{c}$ crystallographic sites for Li2 instead of one $12 d$ site. A fit of the diffraction data to this model, with independent refinement of both $\mathrm{Li} 2 \mathrm{a}$ and $\mathrm{Li} 2 \mathrm{~b} 6 \mathrm{c}$ occupancies, did not result in an improved fit. The $P 6_{3} m c$ model was therefore used for final refinement. MEM analysis also supports the displacement of Li1 and Li2 positions (Figure S6). The final refinement is shown in Figure $4 \mathrm{~b}$ and the refined structural parameters are provided in Table S7. The refined composition is $\mathrm{Li}_{5.82(4)} \mathrm{Si}_{1.00} \mathrm{O}_{3.934(6)} \mathrm{Cl}_{1.956(4)}$ and the $\mathrm{HT}$-phase will therefore be denoted $\mathrm{HT}-\mathrm{Li}_{6} \mathrm{SiO}_{4} \mathrm{Cl}_{2}$ hereafter for simplicity.

\subsubsection{High temperature phase - Structure description}

The $\mathrm{HT} \quad \mathrm{P}_{3} m c$ structure can be described as a $4 \mathrm{H}$ hexagonal anti-perovskite of general formula $\mathrm{ABX}_{3}$, with structural similarities to $4 \mathrm{H}-\mathrm{BaMnO}_{3}$ (Figure $2 \mathrm{~b}$ ) in which half of the $\mathrm{B}$ sites are vacant. This is consistent with cation-deficient hexagonal perovskites with the formula $A_{2} B X_{6}$, such as $R_{2} \mathrm{MnF}_{6}$ with $\mathrm{P}_{3} m c$ symmetry. ${ }^{51}$ The $\mathrm{HT}$ structure of $\mathrm{Li}_{6} \mathrm{SiO}_{4} \mathrm{Cl}_{2}$, consisting of alternating hexagonally stacked $\mathrm{Li}_{3} \mathrm{Cl}$ and $\mathrm{Li}_{3} \mathrm{SiO}_{4}$ layers, is shown in Figure 5b. The (poly)anion network in the HT-structure remains unchanged through the phase transition from the RTstructure, with the observed symmetry change originating from displacements in Li positions. The lithium environments remain tetrahedral $\left(\mathrm{LiO}_{2} \mathrm{Cl}_{2}\right)$ with lithium atoms displaced towards the oxygens, due to its smaller ionic radius compared to chlorine. $\mathrm{Li}-\mathrm{Cl}$ bond lengths vary from $2.366(3) \AA$ to $2.908(8) \AA$, and $\mathrm{Li}$-O bond lengths range from 1.847(4) $\AA$ to 1.942(4) $\AA$ (Figure 5d).

As shown in Figures $5 \mathrm{c}$ and $5 \mathrm{~d}$, the ordered lithium atoms of $\mathrm{RT}-\mathrm{Li}_{6} \mathrm{SiO}_{4} \mathrm{Cl}_{2}$ are disordered in the higher symmetry HT-structure. Similar to the results from normal mode calculations described in Section 4.1., this order-disorder transition occurs via activation of occupational $\mathrm{M}_{2}$ and $\Gamma_{5}$ modes, with a small contribution from displacive $\Gamma_{5}$ modes that predominantly involve displacement of the $\mathrm{Li} 1$ atoms within the close-packed $\mathrm{Li}_{3} \mathrm{SiO}_{4}$ layer (Figure $\mathrm{S} 10$ ). This disorder of the $A$ cation positions is well-known in $A_{(12-n-y) / m}^{m+} L_{6-y}^{n+} X_{6-y}^{2-} Y_{y}^{-}$argyrodites, ${ }^{52,53}$ and provides a direct comparison of $\mathrm{Li}$ disorder between oxide and sulphide argyrodite materials. The delocalisation of Li positions in $\mathrm{HT}$ - $\mathrm{Li}_{6} \mathrm{SiO}_{4} \mathrm{Cl}_{2}$ resembles that observed in high-temperature $F \overline{4} 3 m$ cubic argyrodites $\mathrm{Li}_{6} \mathrm{PS} 5{ }_{5} X(X=\mathrm{Cl}, \mathrm{Br}, \mathrm{I})$, in which Li partially occupies both tetrahedral and trigonal planar coordination environments (48h and $24 g$ Wyckoff 
sites, respectively, Figure S9c), and is one of the reasons for reduced energy barriers for bulk Li ion transport in these materials. ${ }^{8}$

The order-disorder transition of $\mathrm{Li}_{6} \mathrm{SiO}_{4} \mathrm{Cl}_{2}$ (Figure $5 \mathrm{c}$ and $5 \mathrm{~d}$ ) is similar to the behaviour of many argyrodites; $\mathrm{Cu}_{8} \mathrm{GeSe}_{6}$ displays an order-disorder transition between $P 6_{3} \mathrm{~cm}$ and $P 6_{3} m c$ structures, where $\mathrm{Cu}$ ions are disordered in the latter similarly to $\mathrm{Li}$ on the $6 \mathrm{c}$ and $12 d$ Wyckoff positions in $\mathrm{Li}_{6} \mathrm{SiO}_{4} \mathrm{Cl}_{2},{ }^{39}, 54$ and analogous behaviour is observed in silver-containing argyrodites. ${ }^{1}$ Specifically, cubic $\mathrm{Li}_{6} \mathrm{PS}_{5} \mathrm{l}$ has ordered lithium positions at low temperature $(<180 \mathrm{~K})$ and a disordered structure at $298 \mathrm{~K}$ in which lithium is delocalised across the $24 \mathrm{~g}$ and $48 \mathrm{~h}$ positions (Figure 5e), ${ }^{21}$ resulting in comparable local lithium coordination environments with $\mathrm{Li}_{6} \mathrm{SiO}_{4} \mathrm{Cl}_{2}$ (Figure $5 \mathrm{c}$ and $5 \mathrm{~d}$ ) that are consistent with dynamical disorder. This is distinct from the cubic oxide argyrodite, $\mathrm{Li}_{6} \mathrm{PO}_{5} \mathrm{Br}$, in which lithium remains localised on the trigonal planar $24 \mathrm{~g}$ Wyckoff position in the $F \overline{4} 3 \mathrm{~m}$ structure over a wide (173$873 \mathrm{~K}$ ) temperature range (Figure $1 \mathrm{~d}$ ). ${ }^{48}$ Stabilisation of this lithium disorder which enables access to higher energy sites in $\mathrm{Li}_{6} \mathrm{SiO}_{4} \mathrm{Cl}_{2}$ would increase lithium ion migration compared against the room temperature structure.

\subsection{Transport properties}

The ionic conductivity of $\mathrm{Li}_{6} \mathrm{SiO}_{4} \mathrm{Cl}_{2}$ was investigated through $\mathrm{AC}$ impedance spectroscopy on a sintered white pellet of $\sim 84 \%$ theoretical density (pellet cold-pressed under $125 \mathrm{MPa}$ and sintered in evacuated silica ampoule for $12 \mathrm{~h}$ at $848 \mathrm{~K}$ ). A typical set of data measured at $533 \mathrm{~K}$ in inert atmosphere are shown in Figure 7a. The impedance complex plane plots, $Z^{*}$, consist of a high-frequency arc with the presence of a small low-frequency inclined spike. The large single arc is attributed to the sample bulk, as shown by overlapping peaks in the combined Z"/M" spectra (Figure S12a). The associated capacitance of the high-frequency arc, $0.6 \mathrm{pF} \mathrm{cm}^{-1}$, corresponding to a permittivity of $\sim 6.8$, is also consistent with the grain response (Figure $S 12 b$ ). The low-frequency spike is attributed to the double-layer capacitance at the blocking sample-electrode interface, where Li ions cannot pass. To a first approximation, the high-frequency arc could be modelled with an equivalent circuit consisting of a resistor in parallel with a constant phase element (CPE). Impedance data were fitted to the equivalent circuit using ZView software (Figure 7a). In general, the material is homogeneous and shows a total conductivity of $6.2 \times 10^{-6} \mathrm{~S} \mathrm{~cm}^{-1}$ at $575 \mathrm{~K}$ and $\sim 10^{-10} \mathrm{~S} \mathrm{~cm}^{-1}$ at room temperature. DC polarisation measurements show a low electronic contribution of $>0.5 \%$ at $300^{\circ} \mathrm{C}$ to the overall conductivity (Figure S13). From the low-frequency intercept of the impedance arc on the $Z^{\prime}$ axis, values of the total resistance were obtained and are shown in Arrhenius format in Figure 7b. A change in slope can be observed above $\sim 498 \mathrm{~K}$, agreeing with the phase transition observed via VT-XRD and DSC experiments. The orthorhombic phase (red circles) and the hexagonal phase (black squares) have activation energies of $0.560(8) \mathrm{eV}$ and $0.444(9) \mathrm{eV}$, respectively.

The local ionic mobility of lithium was investigated through ${ }^{7} \mathrm{Li}$ solid-state NMR. The temperature dependence of the static ${ }^{7} \mathrm{Li}$ NMR spectra of $\mathrm{Li}_{6} \mathrm{SiO}_{4} \mathrm{Cl}_{2}$ over the temperature range of $331-593 \mathrm{~K}$ is shown in Figure $7 \mathrm{c}$. At temperatures where ion mobility is minimal i.e., the rigid lattice regime, the $1 / 2 \leftrightarrow-1 / 2$ central transition is broadened by ${ }^{7} \mathrm{Li}-{ }^{7} \mathrm{Li}$ homonuclear dipolar coupling. For $\mathrm{Li}_{6} \mathrm{SiO}_{4} \mathrm{Cl}_{2}$, this region is between 350 and $450 \mathrm{~K}$, where the linewidth of the central transition is $\sim 5.5 \mathrm{kHz}$. As the temperature is increased above $450 \mathrm{~K}$, the linewidth decreases drastically over a small temperature range (Figure 7d) due to the increasing motion of the Li spins continuously averaging the dipolar interactions, and clearly evidences an increase in ionic mobility facilitated by the phase transition from the ordered RT-orthorhombic to the higher symmetry HT-hexagonal phase.

Through calculation of the strength of ${ }^{7} \mathrm{Li}-{ }^{7} \mathrm{Li}$ homonuclear dipolar coupling of both the room temperature and high temperature phases of $\mathrm{Li}_{6} \mathrm{SiO}_{4} \mathrm{Cl}_{2}$, further insight into the local ion dynamics of the two phases can be determined. 
By extracting the shortest Li-Li distance from the SXRD data (Li1-Li5, 2.697(6) $\AA$ ), the (absolute value) of the dipolar coupling constant can be calculated (Eq. 1) as $\sim 5.8 \mathrm{kHz}$ in $\mathrm{RT}-\mathrm{Li}_{6} \mathrm{SiO}_{4} \mathrm{Cl}_{2}$ in full agreement with the experimental linewidth observed, while $\sim 8.2 \mathrm{kHz}$ is obtained from $\mathrm{Li} 1 \mathrm{a}$ and $\mathrm{Li} 2$ (2.410(5) $\AA$ ) for $\mathrm{HT}-\mathrm{Li}_{6} \mathrm{SiO}_{4} \mathrm{Cl}_{2}$. Due to the increase in dipolar coupling after the phase transition, it would be expected that ${ }^{7} \mathrm{Li}$ spectra would demonstrate increased linewidths at higher $\mathrm{T}$ in the absence of an increase of Li ion mobility. However, the line narrowing observed (Figure 7d) is a clear indication that the phase transition from the RT-orthorhombic phase to the higher symmetry HThexagonal phase facilitates an increase in Li ion mobility, as also observed in AC impedance measurements (Figure 7b). The lithium positions in the orthorhombic RT structure are fully ordered. The delocalisation of lithium in HT$\mathrm{Li}_{6} \mathrm{SiO}_{4} \mathrm{Cl}_{2}$ across the $6 c$ and $12 d$ sites (Figure $5 \mathrm{c}$ and $5 \mathrm{~d}$ ) results in a lowering of the activation energy from RT$\mathrm{Li}_{6} \mathrm{SiO}_{4} \mathrm{Cl}_{2}$. The activation energies obtained from $\mathrm{Li}_{6} \mathrm{SiO}_{4} \mathrm{Cl}_{2}$ are lower than those extracted from $\mathrm{Li}_{6} \mathrm{PO}_{5} \mathrm{Cl}$ across the measured temperature range, despite the latter adopting the higher symmetry cubic $F \overline{4} 3 m$ structure. ${ }^{9}$
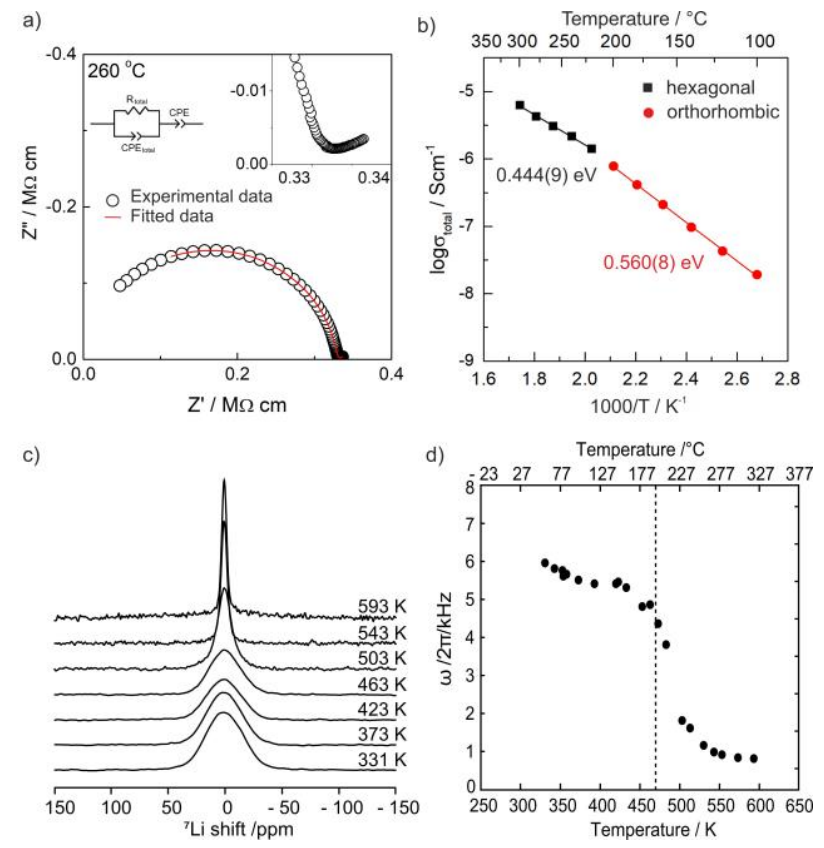

Figure 7. a) Impedance complex plane plots $\mathrm{Z}^{*}$ of $\mathrm{Li}_{6} \mathrm{SiO}_{4} \mathrm{Cl}_{2}$ at $533 \mathrm{~K}$, inset shows equivalent circuit used to model the data. The inset shows the low frequency inclined spike attributed to the capacitance of the blocking electrode. (b) Arrhenius plots of the total conductivity, activation energies derived from the data are shown. A change in Arrhenius behaviour and activation energy can be seen at $\sim 470 \mathrm{~K}$ corresponding to the phase change observed in VT-XRD and DSC measurements. c) ${ }^{7}$ Li NMR spectra under static conditions as a function of temperature. d) Motional narrowing of the line width (full width at half-maximum) of the central ${ }^{7}$ Li NMR transition. The temperature at which the phase change is detected via DSC measurements is also noted (dashed line).

The distinction between the oxide materials $\mathrm{Li}_{6} \mathrm{SiO}_{4} \mathrm{Cl}_{2}$ and $\mathrm{Li}_{6} \mathrm{PO}_{5} \mathrm{Cl}$ is likely the increased size of the trigonal anion window (Figure 5f) and the associated dynamical $\mathrm{Li}$ disorder (absent in cubic $\mathrm{Li}_{6} \mathrm{PO}_{5} \mathrm{Cl}$, where $\mathrm{Li}$ is localised on the $24 \mathrm{~g}$ position) in hexagonal $\mathrm{Li}_{6} \mathrm{SiO}_{4} \mathrm{Cl}_{2}$ (partial occupancy of $6 \mathrm{c}$ and $12 d$ positions by $\mathrm{Li}$ ), leading to lower activation energies for ion mobility. Local jumps of $\mathrm{Li}^{+}$between these tetrahedral sites separated by the trigonal anion windows are the most favourable for ionic diffusion in argyrodites. ${ }^{8}$ Occupational disorder via chalcogenide-halide mixing on the anion position that forms part of the trigonal window that mobile cations traverse (Figure $5 f$ ) is an important route to enhancing $\mathrm{Li}$ ion mobility. ${ }^{12,55} \mathrm{Unlike} \mathrm{Li}_{6} \mathrm{PO}_{5} \mathrm{Cl}$, where this window is formed from three oxide anions, the 
$\mathrm{LiCl}_{2} \mathrm{O}_{2}$ environments of $\mathrm{Li}_{6} \mathrm{SiO}_{4} \mathrm{Cl}_{2}$ yield a window described by one chloride and two oxide anions. The larger $\mathrm{Cl}$ $\left(r_{C l}=1.81 \AA, r_{\mathrm{O}}=1.40 \AA\right)^{45}$ increases the size of this window, further lowering the activation energy of ion transport compared to $\mathrm{Li}_{6} \mathrm{PO}_{5} \mathrm{Cl}$.

\section{Conclusion}

The connection between argyrodite and anti-perovskite structures is established, thus identifying close-packed layers that can be assembled through the diversity of combined hexagonal and cubic stacking operations known to give the perovskite materials family its breadth of scientific and technological importance. We exemplify these mixed stackings in the hexagonal argyrodite materials family through the prediction then isolation of the non-toxic and earth abundant $\mathrm{Li}_{6} \mathrm{SiO}_{4} \mathrm{Cl}_{2}$. Here the resulting layer stacking gives access to the disordered $\mathrm{Li}$ distribution which is observed in fast lithium ion conductors, a distribution not accessible to its nearest known cubic compositional counterpart, $\mathrm{Li}_{6} \mathrm{PO}_{5} \mathrm{Cl}$. Exploration of the many accessible mixed layer sequences and associated site and chemical orderings afforded within this family opens new routes to the tuning and creation of ion transport pathways through variation of both composition and structure, as well as broader functional outcomes based on the importance of the cubic argyrodite materials.

\section{Acknowledgements}

We are grateful to the ISCF Faraday Challenge project "SOLBAT - The Solid-State (Li or Na) Metal-Anode Battery" [grant number FIRG007] for funding Y. D., the studentship of A. M., and partial studentship support of B. B. D., who is also supported by the University of Liverpool. This work used the Cirrus UK National Tier-2 HPC Service at EPCC (http://www.cirrus.ac.uk) funded by the University of Edinburgh and EPSRC (EP/P020267/1), along with the University of Liverpool HPC cluster, Barkla. We thank EPSRC for funding G. H. and J. G. under EP/N004884, and for funding T. W. S. under EP/R011753/1. This work was carried out with the support of Diamond Light Source, instrument I11 (proposal CY23666).

\section{Supporting information}

Computed decomposition energies of the compounds $\mathrm{Li}_{6} \mathrm{SiO}_{4} \mathrm{XX}^{\prime}(\mathrm{X}=\mathrm{F}, \mathrm{Cl}, \mathrm{Br}$, I) for different space groups, PXRD patterns for $\mathrm{Li}_{6} \mathrm{SiO}_{4} \mathrm{Cl}_{2-\times} \mathrm{Br}_{\mathrm{x}}$, Pawley fits (RT and $\mathrm{HT}$ phase), comparison of Rietveld refinement before and after refinement of atomic positions as well as with and without $L i$ atoms (RT phase), MEM analysis (RT and HT phase), comparison of computed and experimental structures (RT and HT phase), Fourier difference map (HT phase), structural information of $\mathrm{Li}_{6} \mathrm{SiO}_{4} \mathrm{Cl}_{2}$ determined by single crystal diffraction and powder diffraction refinement (refinement details, atomic positions, bond distances and angles), additional ${ }^{29} \mathrm{Si}$ NMR and impedance results are available.

Underlying data are available at http://datacat.liverpool.ac.uk/id/eprint/1158.

The crystal structure of $\mathrm{Li}_{6} \mathrm{SiO}_{4} \mathrm{Cl}_{2}$ is deposited with the CSD 2032155.

\section{References}

1. Kuhs, W.; Nitsche, R.; Scheunemann, K. The argyrodites-A new family of tetrahedrally close-packed structures. Mater. Res. Bull. 1979, 14, 241-248.

2. Wada, $\mathrm{H}$. Crystal structures and silver ionic conductivities of the new compounds $\mathrm{Ag}_{7} \mathrm{NbS}_{6}, \mathrm{Ag}_{7} \mathrm{TaSe}_{6}$ and $\mathrm{Ag}_{7-\xi} \mathrm{TaSe}_{6-\xi} \mathrm{l}_{\xi}(0.1 \leqslant \xi \leqslant 0.5)$. J. Alloys Compd. 1992, 178, 315-323. 
3. Li, L.; Liu, Y.; Dai, J.; Hong, A.; Zeng, M.; Yan, Z.; Xu, J.; Zhang, D.; Shan, D.; Liu, S. High thermoelectric performance of superionic argyrodite compound $\mathrm{Ag}_{8} \mathrm{SnSe}_{6}$. J. Mater. Chem. C 2016, 4, 5806-5813.

4. Gaudin, E.; Boucher, F.; Petricek, V.; Taulelle, F.; Evain, M. Structures and phase transitions of the

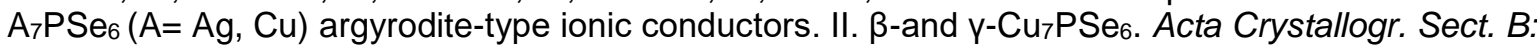
Struct. Sci. 2000, 56, 402-408.

5. Evain, M.; Gaudin, E.; Boucher, F.; Petricek, V.; Taulelle, F. Structures and phase transitions of the $\mathrm{A}_{7} \mathrm{PSe}_{6}(\mathrm{~A}=\mathrm{Ag}, \mathrm{Cu})$ argyrodite-type ionic conductors. I. Ag7 $\mathrm{PSe}_{6}$. Acta Crystallogr. Sect. B: Struct. Sci. 1998, 54, 376-383.

6. Rao, R. P.; Adams, S. Studies of lithium argyrodite solid electrolytes for all-solid-state batteries. Phys. Status Solidi A 2011, 208, 1804-1807.

7. Deiseroth, H. J.; Kong, S. T.; Eckert, H.; Vannahme, J.; Reiner, C.; Zaiß, T.; Schlosser, M. Li 6 PS ${ }_{5} \mathrm{X}$ : a class of crystalline Li-rich solids with an unusually high Li+ mobility. Angew. Chem., Int. Ed. 2008, 120, 767-770.

8. Deiseroth, H. J.; Maier, J.; Weichert, K.; Nickel, V.; Kong, S. T.; Reiner, C. Li $\mathrm{I}_{7} \mathrm{PS}_{6}$ and $\mathrm{Li}_{6} \mathrm{PS} 5 \mathrm{X}$ (X: Cl, Br, I): Possible Three-dimensional Diffusion Pathways for Lithium lons and Temperature Dependence of the Ionic Conductivity by Impedance Measurements. Z. Anorg. Allg. Chem. 2011, 637, 1287-1294.

9. Kong, S. T.; Deiseroth, H. J.; Maier, J.; Nickel, V.; Weichert, K.; Reiner, C. Li6 $\mathrm{PO}_{5} \mathrm{Br}$ and $\mathrm{Li}_{6} \mathrm{PO}_{5} \mathrm{Cl}$ : The first Lithium-Oxide-Argyrodites. Z. Anorg. Allg. Chem. 2010, 636, 1920-1924.

10. De Klerk, N. J.; Rosłoń, I.; Wagemaker, M. Diffusion mechanism of Li argyrodite solid electrolytes for Liion batteries and prediction of optimized halogen doping: the effect of Li vacancies, halogens, and halogen disorder. Chem. Mater. 2016, 28, 7955-7963.

11. Kraft, M. A.; Culver, S. P.; Calderon, M.; Böcher, F.; Krauskopf, T.; Senyshyn, A.; Dietrich, C.; Zevalkink, A.; Janek, J. r.; Zeier, W. G. Influence of lattice polarizability on the ionic conductivity in the lithium superionic argyrodites $\mathrm{Li}_{6} \mathrm{PS} \mathrm{S}_{5} \mathrm{X}(\mathrm{X}=\mathrm{Cl}, \mathrm{Br}$, I). J. Am. Chem. Soc. 2017, 139, 10909-10918.

12. Minafra, N.; Culver, S. P.; Krauskopf, T.; Senyshyn, A.; Zeier, W. G. Effect of Si substitution on the structural and transport properties of superionic Li-argyrodites. J. Mater. Chem. A 2018, 6, 645-651.

13. Zhao, Y.; Daemen, L. L. Superionic conductivity in lithium-rich anti-perovskites. J. Am. Chem. Soc. 2012, $134,15042-15047$.

14. Kresse, G.; Furthmüller, J. Efficient iterative schemes for ab initio total-energy calculations using a plane-wave basis set. Phys. Rev. B 1996, 54, 11169.

15. Kresse, G.; Joubert, D. From ultrasoft pseudopotentials to the projector augmented-wave method. Phys. Rev. B 1999, 59, 1758.

16. Perdew, J. P.; Burke, K.; Ernzerhof, M. Generalized gradient approximation made simple. Phys. Rev. Lett. 1996, 77, 3865.

17. Perdew, J. P.; Ruzsinszky, A.; Csonka, G. I.; Vydrov, O. A.; Scuseria, G. E.; Constantin, L. A.; Zhou, X.; Burke, K. Restoring the density-gradient expansion for exchange in solids and surfaces. Phys. Rev. Lett. 2008, 100, 136406.

18. Ong, S. P.; Richards, W. D.; Jain, A.; Hautier, G.; Kocher, M.; Cholia, S.; Gunter, D.; Chevrier, V. L.; Persson, K. A.; Ceder, G. Python Materials Genomics (pymatgen): A robust, open-source python library for materials analysis. Comp. Mater. Sci. 2013, 68, 314-319.

19. Deng, Z.; Wang, Z.; Chu, I.-H.; Luo, J.; Ong, S. P. Elastic properties of alkali superionic conductor electrolytes from first principles calculations. J. Electrochem. Soc. 2015, 163, A67.

20. Wortmann, R.; Sitta, S.; Sabrowsky, H. $\mathrm{Li}_{7} \mathrm{O}_{2} \mathrm{Br}_{3}$-Eine weitere Strukturvariante der neuen Alkalimetallchalkogenidhalogenid-Perowskite/ $\mathrm{Li}_{7} \mathrm{O}_{2} \mathrm{Br}_{3}-\mathrm{A}$ Further Structure Variant of the New Alkali Metal Chalcogenide Halide Perovskites. Z. Naturf. B 1989, 44, 1348-1350.

21. Kong, S. T.; Deiseroth, H. J.; Reiner, C.; Gün, Ö.; Neumann, E.; Ritter, C.; Zahn, D. Lithium argyrodites with phosphorus and arsenic: order and disorder of lithium atoms, crystal chemistry, and phase transitions. Chem. Eur. J. 2010, 16, 2198-2206.

22. Tang, T.; Zhang, Z.; Meng, J.-B.; Luo, D.-L. Synthesis and characterization of lithium silicate powders. Fus. Eng. Des. 2009, 84, 2124-2130.

23. Thompson, S.; Parker, J.; Potter, J.; Hill, T.; Birt, A.; Cobb, T.; Yuan, F.; Tang, C. Beamline I11 at Diamond: A new instrument for high resolution powder diffraction. Rev. Sci. Instrum. 2009, 80, 075107.

24. Coelho, A. Whole-profile structure solution from powder diffraction data using simulated annealing. $J$. Appl. Crystallogr. 2000, 33, 899-908.

25. CrysAlisPro Software System, Version 1.171.38.41.Rigaku Oxford Diffraction Ltd, Yarnton, Oxfordshire, England. (2015).

26. Dolomanov, O. V.; Bourhis, L. J.; Gildea, R. J.; Howard, J. A.; Puschmann, H. OLEX2: a complete structure solution, refinement and analysis program. J. Applied Crystallogr. 2009, 42, 339-341.

27. Sheldrick, G. M. SHELXT-Integrated space-group and crystal-structure determination. Acta Crystallogr. Sect. A: Found. Adv. 2015, 71, 3-8.

28. Sheldrick, G. M. Crystal structure refinement with SHELXL. Acta Crystallogr. Sect. C: Struct. Chem. 2015, 71, 3-8. 
29. Johnson, D. ZView: A Software Program for IES Analysis 3.5 d. In Scribner Associates Inc: 2007.

30. Brendler, E.; Heine, T.; Hill, A. F.; Wagler, J. A pentacoordinate chlorotrimethylsilane derivative: a very polar snapshot of a nucleophilic substitution and its influence on ${ }^{29} \mathrm{Si}$ solid state NMR properties. $Z$. Anorg. Allg. Chem. 2009, 635, 1300-1305.

31. Beckmann, P. A.; Dybowski, C. A thermometer for nonspinning solid-state NMR spectroscopy, J. Magn. Reson. 2000, 146, 379.

32. Becker, K. Temperature dependence of NMR chemical shifts in cuprous halides. J. Chem. Phys. 1978, 68, 3785-3793.

33. Wu, J.; Kim, N.; Stebbins, J. F. Temperature calibration for high-temperature MAS NMR to $913 \mathrm{~K}:{ }^{63} \mathrm{Cu}$ MAS NMR of $\mathrm{CuBr}$ and Cul, and ${ }^{23} \mathrm{Na} \mathrm{MAS} N M R$ of $\mathrm{NaNbO}_{3}$. Solid State Nucl. Magn. Reson. 2011, 40, 45-50.

34. Petříček, V.; Dušek, M.; Palatinus, L. Crystallographic computing system JANA2006: general features. Z. Kristallogr. 2014, 229, 345-352.

35. Smaalen, S. v.; Palatinus, L.; Schneider, M. The maximum-entropy method in superspace. Acta Crystallogr. Sect. A: Found. Crystallogr. 2003, 59, 459-469.

36. Momma, K.; Izumi, F. VESTA 3 for three-dimensional visualization of crystal, volumetric and morphology data. J. Applied Crystallogr. 2011, 44, 1272-1276.

37. Abramov, Y. A.; Tsirelson, V.; Zavodnik, V.; Ivanov, S.; Brown, I. The chemical bond and atomic displacements in $\mathrm{SrTiO}_{3}$ from X-ray diffraction analysis. Acta Crystallogr. Sect. B: Struct. Sci. 1995, 51, 942-951.

38. Williams, R.; Dillin, D. R.; Milligan, W. Structure refinement of potassium chloroplatinate by powder and single-crystal methods. Acta Crystallogr. Sect. B: Struct. Crystallogr. Cryst. Chem. 1973, 29, 1369-1372.

39. Jaulmes, S.; Julien-Pouzol, M.; Laruelle, P.; Rivet, J. Varietes de haute et basse temperature du seleniure double de cuivre et de germanium. Acta Crystallogr. Sect. C: Cryst. Struct. Commun. 1991, 47, 1799-1803.

40. Onoda, M.; Ishii, M.; Pattison, P.; Shibata, K.; Yamamoto, A.; Chapuis, G. Superspace-group approach to the phase transition of $\mathrm{Cu}_{8} \mathrm{GeSe}_{6}$. J. Solid State Chem. 1999, 146, 355-362.

41. Jiang, B.; Qiu, P.; Eikeland, E.; Chen, H.; Song, Q.; Ren, D.; Zhang, T.; Yang, J.; Iversen, B. B.; Shi, X. $\mathrm{Cu}_{8} \mathrm{GeSe}_{6}$-based thermoelectric materials with an argyrodite structure. J. Mater. Chem. C 2017, 5, $943-$ 952.

42. Jablonska, M.; Pfitzner, A. Preparation and crystal structure of $(\mathrm{Agl})_{2} \mathrm{Ag}_{3} \mathrm{PS}$. Z. Anorg. Allg. Chem. 2004, 630, 1731.

43. Hofmann, R.; Hoppe, R. Ein neues Oxogermanat: $\mathrm{Li}_{8} \mathrm{GeO}_{6}=\mathrm{Li}_{8} \mathrm{O}_{2}\left[\mathrm{GeO}_{4}\right]$. (Mit einer Bemerkung über $\mathrm{Li}_{8} \mathrm{SiO}_{6}$ und $\mathrm{Li}_{4} \mathrm{GeO}_{4}$ ). Z. Anorg. Allg. Chem. 1987, 555, 118-128.

44. Gäbler, F.; Niewa, R. Stacking Design of Inverse Perovskites: The Systems ( $\left.\mathrm{Sr}_{3-\times \mathrm{Ba}} \mathrm{N}\right) \mathrm{E}, \mathrm{E}=\mathrm{Bi}, \mathrm{Sb}$. Inorg. Chem. 2007, 46, 859-865.

45. Shannon, R. D. Revised effective ionic radii and systematic studies of interatomic distances in halides and chalcogenides. Acta Crystallogr. Sect. A: Cryst. Phys. Diffr. Theor. Gen. Crystallogr. 1976, 32, 751767.

46. Potoff, A. D.; Chamberland, B. L.; Katz, L. A single crystal study of eight-layer barium managanese oxide, $\mathrm{BaMnO}_{3}$. J. Solid State Chem. 1973, 8, 234-237.

47. Monroe, C.; Newman, J. The impact of elastic deformation on deposition kinetics at lithium/polymer interfaces. J. Electrochem. Soc. 2005, 152, A396.

48. Kim, K. J.; Balaish, M.; Wadaguchi, M.; Kong, L.; Rupp, J. L. M. Solid-State Li-Metal Batteries: Challenges and Horizons of Oxide and Sulfide Solid Electrolytes and Their Interfaces. Adv. Energy Mater. 2021, 11, 2002689.

49. Tranqui, D.; Shannon, R.; Chen, H.-Y.; lijima, S.; Baur, W. Crystal structure of ordered $\mathrm{Li}_{4} \mathrm{SiO}_{4}$. Acta Crystallogr. Sect. B: Struct. Crystallogr. Cryst. Chem. 1979, 35, 2479-2487.

50. Partik, M.; Schneider, M.; Lutz, H. Kristallstrukturen von $\mathrm{MgCr}_{2} \mathrm{O}_{4}-\mathrm{Typ} \mathrm{Li}_{2} \mathrm{VCl}_{4}$ und Spinell-Typ $\mathrm{Li}_{2} \mathrm{MgCl}_{4}$ und $\mathrm{Li}_{2} \mathrm{CdCl}_{4}$. Z. Anorg. Allg. Chem. 1994, 620, 791-795.

51. Schippers, A.; Brandwijk, V.; Gorter, E. Derivation and discussion of crystal structures of compounds $A B X_{3}$ and $A_{2} B X_{6}$ : Part I. Derivation of the structures. J. Solid State Chem. 1973, 6, 479-492.

52. Nilges, T.; Pfitzner, A. A structural differentiation of quaternary copper argyrodites: Structure-property relations of high temperature ion conductors. Z. Kristallogr. 2005, 281-294.

53. Albert, S.; Pillet, S.; Lecomte, C.; Pradel, A.; Ribes, M. Disorder in $\mathrm{Ag}_{7} \mathrm{GeSe}_{5} 1$, a superionic conductor: temperature-dependent anharmonic structural study. Acta Crystallogr. Sect. B: Struct. Sci. 2008, 64, 111.

54. Jiang, B.; Qiu, P.; Eikeland, E.; Chen, H.; Song, Q.; Ren, D.; Zhang, T.; Yang, J.; Iversen, B. B.; Shi, X. $\mathrm{Cu}_{8} \mathrm{GeSe}_{6}$-based thermoelectric materials with an argyrodite structure. J. Mater. Chem. C 2017, 5, 943952.

55. Adeli, P.; Bazak, J. D.; Park, K. H.; Kochetkov, I.; Huq, A.; Goward, G. R.; Nazar, L. F. Boosting solidstate diffusivity and conductivity in lithium superionic argyrodites by halide substitution. Angew. Chem., Int. Ed. 2019, 58, 8681-8686. 
For Table of Contents Only
$\mathrm{Li}_{6} \mathrm{PO}_{5} \mathrm{Cl}$
$\mathrm{Li}_{6} \mathrm{SiO}_{4} \mathrm{Cl}_{2}$
$\mathrm{Li}_{3} \mathrm{OCl}$
Cubic Argyrodite Hexagonal Argyrodite Cubic Anti-Perovskite

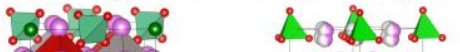

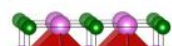
10.0 .0$.

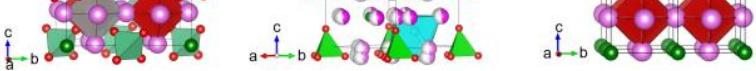

